\title{
París como ciudad semántica en dos novelas gráficas de Jacques Tardi
}

\author{
Edmundo Garrido Alarcón \\ Departamento de Filología Románica, Filología Eslava y Lingüística \\ General \\ Universidad Complutense de Madrid \\ egarrido75@gmail.com
}

Recibido: 17 de octubre de 2011

Aceptado: 16 de noviembre de 2011

\section{Resumen}

Dos novelas gráficas de un mismo autor y de un mismo género, el policial, sirven para comparar dos versiones de París. Basados en obras de dos importantes autores de novela negra, Malet y Manchette, son puestos en relación con sus obras de origen. Situados en dos momentos históricos muy diferentes, la ocupación alemana y los años setenta, la representación visual de la ciudad es analizada y comparada.

Palabras clave: Jacques Tardi, Leo Malet, Jean-Patrick Manchette, Paris, cómic.

Title: Paris as semantic city in two graphic novels by Jacques Tardi

\section{Abstract}

Two graphic novels by the same author and of the same police genre, serve to compare two different versions of the city of Paris. Based on two important French detective novels by Malet and Manchette, they are put in context with their literary sources. Placed in two very different historic moments, the nazi occupation of France and the seventies, the visual representation of the city is analyzed and compared.

Keywords: Jacques Tardi, Leo Malet, Jean-Patrick Manchette, Paris, comic.

\section{Índice}

1. Introducción

2. Tardi

3. Los textos adaptados: dos momentos clave de la novela policíaca francesa

3.1. 120, rue de la Gare

3.2. Le petit bleu de la côte Ouest

4. Adaptación de una narrativa a un discurso mixto

5. Análisis: novelas gráficas

5.1. París en 120, rue de la Gare

5.2. París en Le petit bleu de la côte Ouest

6. Desplazamiento y centro: L'Opéra Garnier 


\section{Introducción}

En este trabajo nos proponemos mostrar la función de lo urbano como trasfondo inevitable de los personajes de novela gráfica, en el desarrollo de las narraciones policiales presentadas en dos obras de Jacques Tardi. De la simple ciudad escenario de la narrativa empujada por diálogos y personajes, este autor potencia su capacidad semántica generando un iconotexto, en términos de Jenaro Talens, donde los diferentes componentes se conjugan, dialogan y generan un espacio textual coherente y complejo, un "espacio del lector", otro de la simple adición de texto e imagen. La comparación de métodos nos permitirá ver también el desplazamiento del centro a la periferia, tanto en términos socio-históricos como simbólicos, de la ciudad semántica, según las narraciones desarrolladas en distintas épocas en la misma ciudad.

\section{Tardi}

Jacques Tardi (Valence, 1946) comienza su desarrollo artístico en el célebre semillero que fue la revista Pilote, pero rápidamente comienza a colaborar con la otra pieza clave del desarrollo del cómic como novela gráfica, la revista Metal Hurlant. Su trabajo alcanza un alto nivel de reconocimiento con cómics situados en la Gran Guerra, en especial Adieu Brandovine, y la serie en torno a una investigadora de lo paranormal Ilamada Adèle Blanc-Sec, también situada en los años de la Belle Époque hasta la Primera Guerra Mundial pero, en este caso, en un París al mismo tiempo realista y fabuloso, donde conviven los resultados de la revolución industrial y las reformas de Haussmann con monstruos y fantasmas.

En 1981 comienza una serie de adaptaciones de novelas negras de Leo Malet, concentrándose en su personaje principal Nestor Burma, que posteriormente continúa con novelistas contemporáneos como Daenickx y Manchette. También ha dedicado varios álbumes a adaptaciones de novelas de Louis-Ferdinand Céline. Sin embargo, en 2001 retoma el trabajo con temas históricos, adaptando la novela Le cri du peuple de Jean Vautrin, situada en el París de la Comuna (y queda pendiente una comparativa más extensa de los cuatro París que se pueden encontrar en Tardi, el de la comuna, la primera guerra, la segunda y el contemporáneo). Su estilo es considerado por la crítica especializada como cercano a la "línea clara" que se origina en el clásico personaje de Hergé, Tintin, en términos del trazo utilizado, pero con una importante diferencia en términos de composición, tintas y densidad narrativa. La "línea clara" se caracteriza por un dibujo limpio, que permite una comprensión rápida e inequívoca de la escena, que funciona de manera paralela a una narrativa también clara, directa $y$, en muchos casos, un tanto sosa por su estructura lineal y la ausencia de matices en los personajes. 
Por el contrario, a pesar de conservar cierta claridad en la composición, en especial en el delineado, huella de su paso por Pilote, el dibujo de Tardi es mucho más oscuro, en su entintado pero también en su complejidad compositiva. Sin llegar al barroco de Geoff Darrow, la plancha de Tardi rompe con la malla tradicional y en muchas ocasiones juega con las expectativas de lectura, de izquierda a derecha, de arriba a abajo, al desordenar los diferentes elementos semánticos de la página. Finalmente, a nivel de guión, Tardi se caracteriza por crear o adaptar personajes que son el opuesto radical del héroe íntegro e inamovible que es el personaje de Hergé. Desde desertores a revolucionarios, pasando por oscuros personajes de novela negra, parecen ser los anti-héroes, en su acepción clásica, pero que pueden ser modelos de una ética "otra". Por ejemplo, el caso del investigador privado Griffú que termina muriendo por defender lo que le parece justo a pesar de ser un personaje de los bajos fondos, que constantemente usa medios ilegales para llegar a encontrar la verdad.

\section{Los textos adaptados: dos momentos clave de la novela policíaca francesa}

La novela policíaca francesa o "polar" (de "roman policier") tuvo un gran desarrollo en la posguerra de la mano del éxito editorial de la Série Noire editada por Gallimard y dirigida por el ex surrealista Marcel Duhamel. Tal furor generó una gran producción local e incluso casos anecdóticos como el del también ex surrealista Boris Vian, quien publicó en esta colección una serie de novelas policiales (bastante delirantes) firmadas con el seudónimo de Vernon Sullivan ya que, por lo visto, los nombres norteamericanos vendían más. Sin embargo, fuera de este periodo bien conocido, hay dos grandes momentos en la historia del polar que se pueden representar por las novelas que adapta Tardi y que veremos reflejadas en las dos obras que operan como hipotextos de los cómics que vamos a leer.

\subsection{0, rue de la Gare}

Según Boileau y Narcejac (1964), autores y teóricos del policial francés, con 120, rue de la gare, Leo Malet introduce el género "negro" en el país. Publicada en 1943, durante la ocupación, dos años antes del fin de la guerra y de la llegada de la Série Noire. Por supuesto es una obra que, al igual que las traducciones y adaptaciones locales, importa buena parte de las atmósferas del crimen donde se cuestionan los límites entre el bien y el mal, así como el orden civil establecido. En este sentido no es casual que Malet, otro viejo poeta surrealista, elija este género para escribir una novela sobre un prisionero de guerra que regresa a la Francia ocupada en 1941, aprovechando para reflejar (en los márgenes, ya 
que la obra se publica bajo la censura de la ocupación) la crisis política y social del grave momento histórico. No llegó a ser exitosa a nivel de ventas por la difícil situación de su aparición y la posterior llegada masiva de novelas americanas, proceso del que Malet, que continuó escribiendo en clave negra, nunca participó. Esto se constata en el hecho de que nunca publicó en la prestigiosa Série Noire.

Según Claire Gorrara, autora de un estudio cultural sobre el impacto de esta narrativa en la sociedad francesa (2003), el estilo de Malet se caracteriza por una combinación de la tradición literaria francesa bien conocida con una lectura de la escritura criminal o hard-boiled norteamericana. Resumiendo mucho la diégesis, ya que nos concentraremos en el aspecto visual de las viñetas, podemos decir que se trata de una clásica trama de intriga o who dunnit, en la que, a pesar de situarse en la Francia ocupada, los alemanes no juegan ningún rol. Sin embargo, la crítica ha querido ver en el crimen y en su solución por parte de Nestor Burma, el soldado que regresa de un campo de prisioneros pero que ya antes de la guerra se dedicaba a trabajar como investigador privado, un velado mensaje de esperanza en la liberación nacional y la reconstrucción de su identidad.

\subsection{Le petit bleu de la côte Ouest}

El segundo momento clave en el desarrollo del género policiaco en Francia surge del desencanto. Viene marcado, después de su nacimiento y explosiva expansión en la posguerra, por un decaimiento producto de la excesiva repetición de moldes y estructuras. Coincide con mayo del 68, que se ha entendido como el catalizador de una generación problemática de autores que dio origen al Ilamado "neo-polar" y cuyo representante más destacado fue JeanPatrick Manchette. En general, son novelas situadas en la Francia posterior a los "trente glorieuses", el milagro económico de la posguerra. El crecimiento productivo tiene un correlato inverso en la sociedad que también se puede ver reflejado en narraciones como Les choses, une histoire des années soixante de Georges Perec (1965), ensayos como La société du spectacle de Guy Debord (1967) y La société de consommation de Jean Baudrillard (1979). Uno de los grandes temas del momento, a nivel de cultura popular, es la llamada "malaise des cadres". Profesionales de clase media, "ejecutivos" de hoy, insertos en un orden burgués dominante, atrapados en unas estructuras estancas. Nuevamente parece ser la crisis social el motor o, al menos, el catalizador de la apertura creativa a nuevas posibilidades formales. En este sentido, el situacionismo, y la obra de Debord a la cabeza, parecen ejercer una gran influencia en las nuevas obras del género. De este modo se puede pensar que en el roman noir se da la paradoja de que una literatura de género, es 
decir convencional por su propia genericidad, se subvierte para operar como literatura contestataria; algo radicalmente opuesto a la función de grata evasión que tenía tradicionalmente este género y otros como la novela histórica o de romance. Mientras Francia se recuperaba del colaboracionismo, la ocupación, el antisemitismo, etc., se vendían por millares historias de detectives, con problemáticas muy diferentes y situadas al otro lado del Atlántico. Por supuesto, tanto las situaciones de policía corrupta como las de discriminación social (blancos y negros), como muchos otros temas, siempre pudieron leerse à clef, como espejo o metáfora de la situación del país, el colaboracionismo (en especial de policía y ejército) y el racismo, pero nunca antes la misma sociedad francesa contemporánea (desde que Malet la utilizara en sus comienzos) había sido el objeto de la narración de manera tan clara. La crítica política que implica el crudo retrato de esta sociedad exitosa pero vacía, junto con unos personajes totalmente exentos de lo que se podría llamar heroicidad, volviendo a los tópicos del relato clásico ${ }^{1}$, ha permitido que la crítica reconozca en este movimiento la última gran revolución del género ${ }^{2}$.

\section{Adaptación de una narrativa a un discurso mixto}

Sin negar que son adaptaciones de textos narrativos, nos interesa concentrarnos en estas obras como objetos independientes. Es decir, no realizar un trabajo comparativo entre hipertexto e hipotexto, en términos de Genette, sino más bien entre dos formas de usar el trasfondo visual de la viñeta para complementar la construcción semántica del discurso narrativo de acuerdo a los dos momentos claves de la narrativa policial francesa antes mencionados.

\section{Análisis: novelas gráficas}

Para hablar de novela gráfica, término acuñado por Will Eisner (2007: 143), no podemos olvidar que nos encontramos ante un campo semántico compuesto de imagen y texto, un iconotexto. Suele

\footnotetext{
${ }^{1}$ También es necesario entender que sus autores, en especial Manchette, están al tanto de la actualidad literaria, por tanto el Nouveau Roman, con Robbe-Grillet escribiendo la novela policial Les gomes, debe ser considerado, a fin de cuentas, como una influencia con su cuestionamiento tanto de la estructura narrativa como de la presencia del autor en el relato.

${ }^{2}$ Como apunte biográfico, se puede mencionar que Tardi y Manchette colaboraron en la creación de Griffú en 1977, es decir, el guión fue creado expresamente para el cómic. Muerto tempranamente de cáncer en 1995, se puede entender la adaptación de Le petit bleu como un homenaje en 2005. Sin embargo, en la introducción a la edición francesa François Guérif indica que los tiempos, para la coherencia del relato, no han cambiado. Tardi apenas deja huellas históricas que diferencien los años setenta de la actualidad, y su descarnada denuncia parece seguir teniendo vigor.
} 
suceder que los análisis desarrollados del cómic desde la academia se centran en el aspecto textual, descuidando el visual, probablemente por falta de una formación interdisciplinar. Como dice Alain Rey, "les modèles actanciels, les isotopies manipulées avec un adresse castratrice par nos sémiologues littéraires restent en deçà de leur objet, dans le sous-sol dénudé du pur récit, avant l'écriture" (1978: 70).

En este caso, por el contrario, nos vamos a centrar en el aspecto visual en su contexto narrativo, el plano visual contra el plano de lectura, comenzando por preguntarnos cómo se representa la ciudad, qué se representa de ella y cuándo, en el marco de la diégesis. Como dice Juan Antonio Ramírez en su estudio Edificios y sueños, al analizar las formas arquitectónicas en el cómic y el cine "hay una selección del complejo material visual que ofrece 'la realidad', y la arquitectura, salvo excepciones, aparece fragmentada" (1991: 210). En los casos que veremos, la arquitectura y el tejido urbano aparecen fragmentados pero con una relevancia que no suele ser común en este medio. De este modo, podremos observar el desplazamiento de la función de la ciudad en dos narrativas policiales con perspectivas diferentes.

\subsection{París en 120, rue de la Gare}

Rápidamente podemos ver que hay dos niveles narrativos superpuestos. La intriga, en los bocadillos y la acción, fiel al texto de Malet, exento de participación o crítica de los invasores alemanes (para lograr superar la censura), y la crítica de la ocupación, desplegada por Tardi en el trasfondo visual de la ciudad. Llenando el campo visual de esvásticas, mensajes antisemitas y soldados, así como la zona "no-no" de Lyon de carteles de Petain (que excluimos para centrarnos en la capital francesa), Tardi explicita en el cómic lo que en la obra de Malet sólo se podía leer de manera implícita en el contexto de la ocupación y que quedó "fuera de campo" al pasar su momento histórico.

La ciudad es un marco preeminente dado su fuerte contenido semántico. De hecho Jean-François Douvry (1988), analizando la adaptación, comenta que el nivel de la crisis francesa es homologable a la crisis norteamericana (la gran depresión) que permitió la aparición de la novela negra en esa sociedad. El simple deambular de Nestor Burma por la ciudad no sólo informa de su ubicación o le permite pensar en la resolución del enigma, sino que conjuga las señas de la ocupación con espacios, en principio simples ubicaciones, que también son lieux de mémoire, como los ha definido Pierre Nora. Es decir, marcadores espaciales insertados en la narrativa de Malet como puntos fuertes de identificación del lector, a pesar de sólo ser mencionados y en el cómic, representados. 

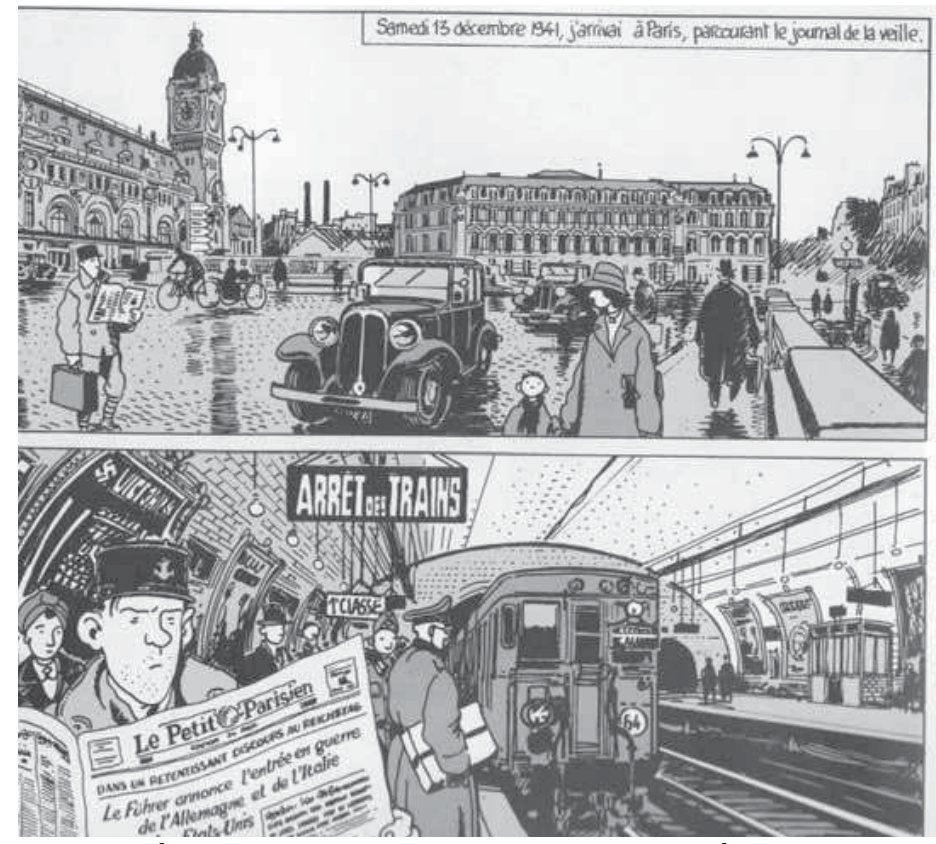

Figura 1. Estación Saint Lazare y Metro de París. Se puede ver una esvástica en el aviso en la pared y en el periódico se anuncia la entrada en guerra entre el "Eje" y los Estados Unidos.

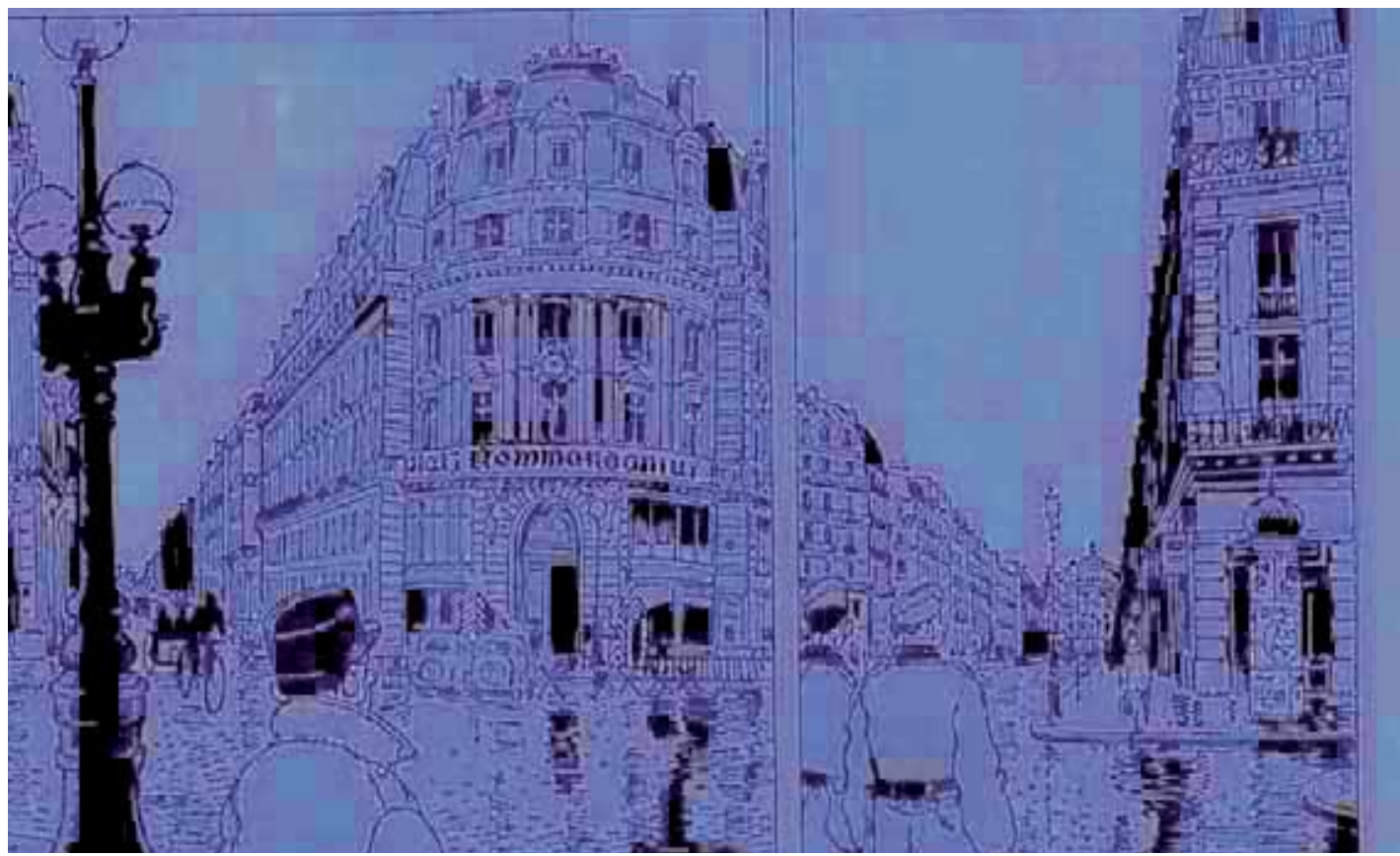

Figura 2. Calles de París. Soldados alemanes, alambradas, carteles en alemán y tipografía gótica. 


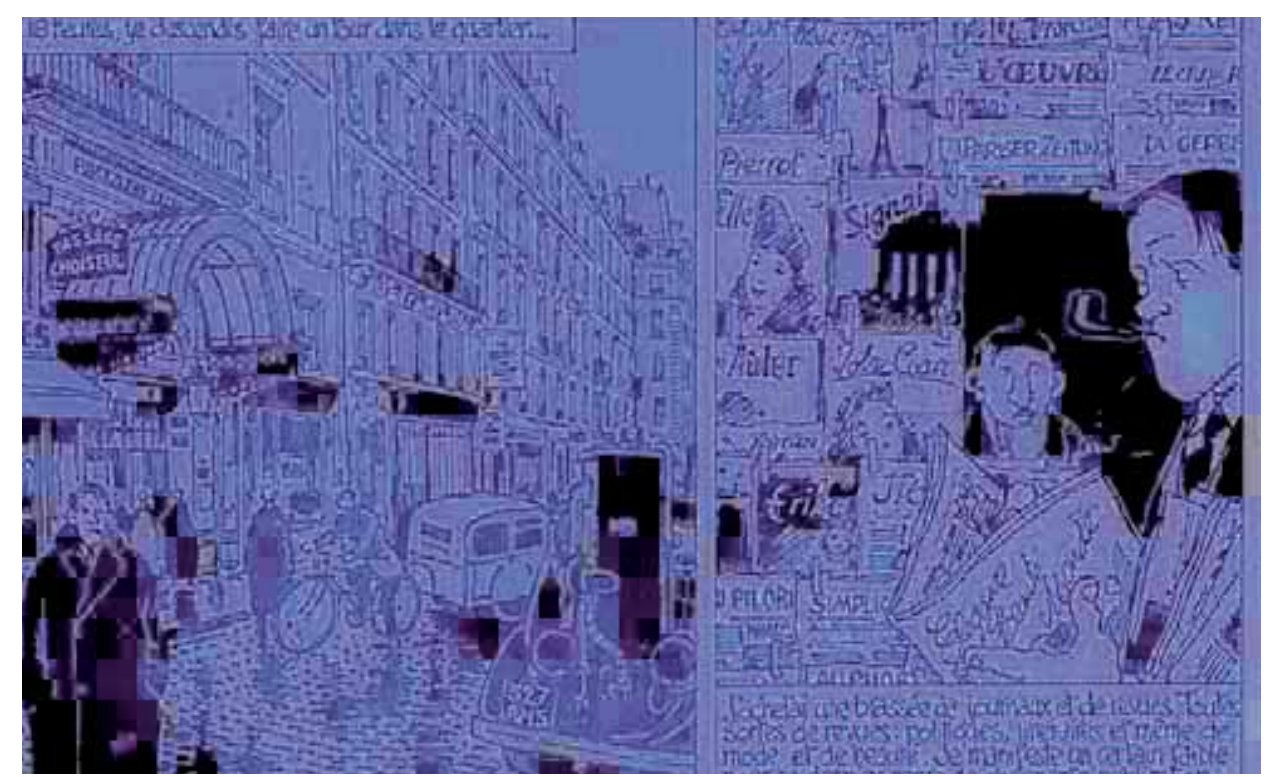

Figura 3. Pasaje Choiseul con un coche "acondicionado" para funcionar sin gasolina y prensa de la época, Nestor Burma ya de civil.

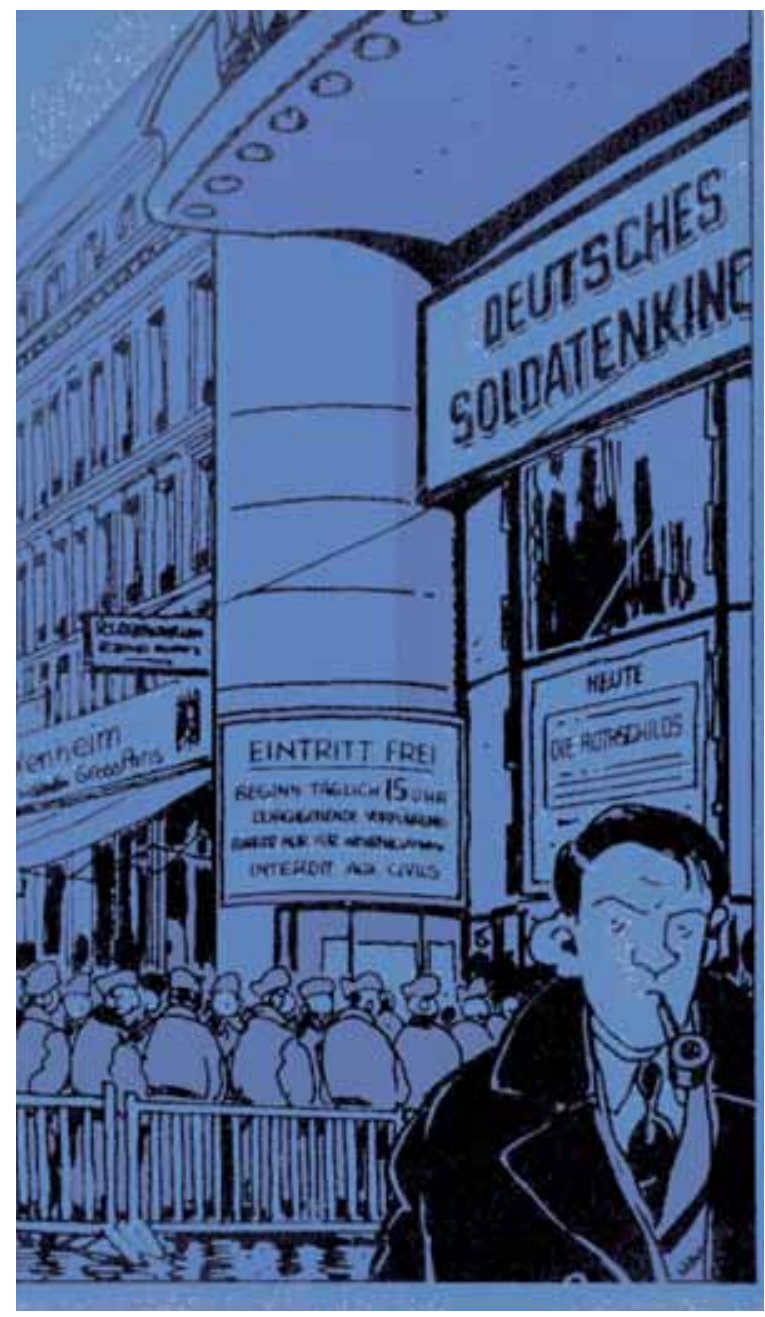

Figura 4. Cine gratuito para soldados alemanes. 

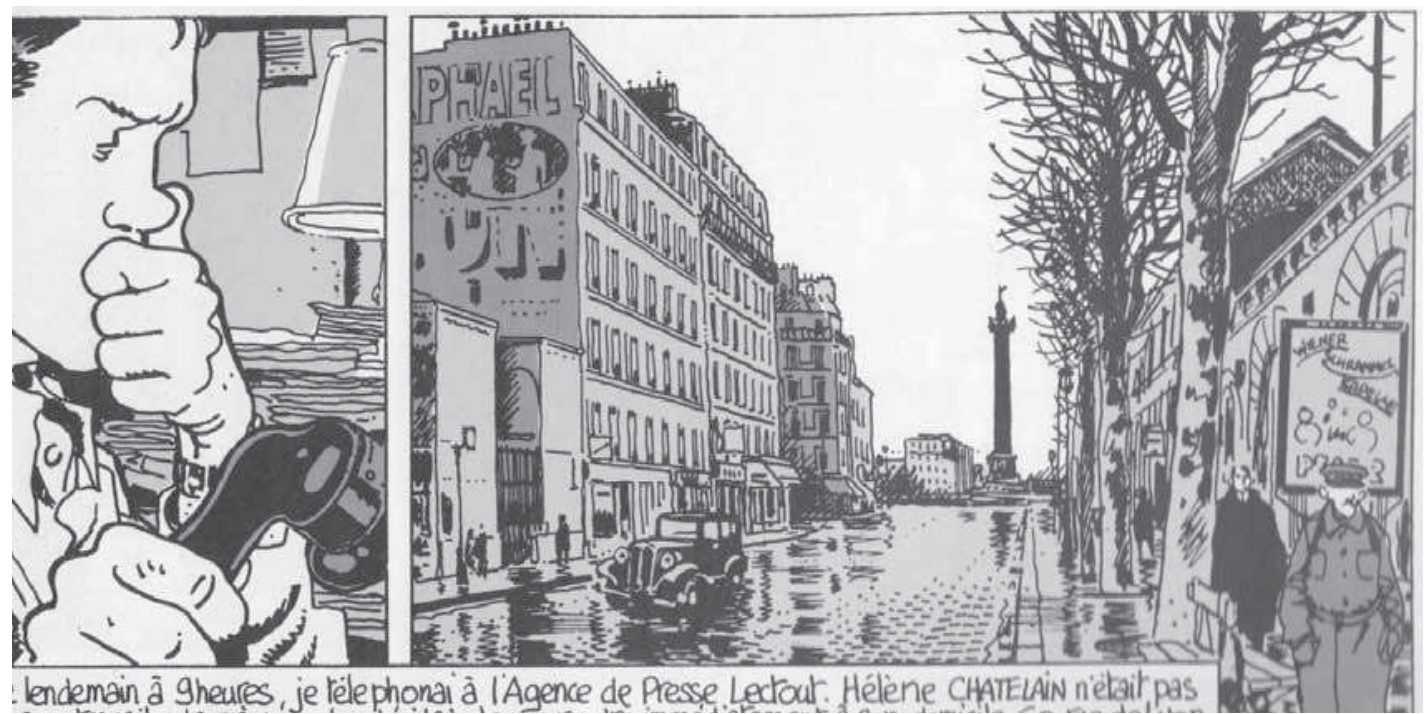

lendemain à gheures, je réle phonai à l'Agence de Presse Lectout: Hélène CHATELAin nétait pas

Figura 5. Av. de Lyon con la significativa vista del monumento de la libertad de la Bastilla al fondo.

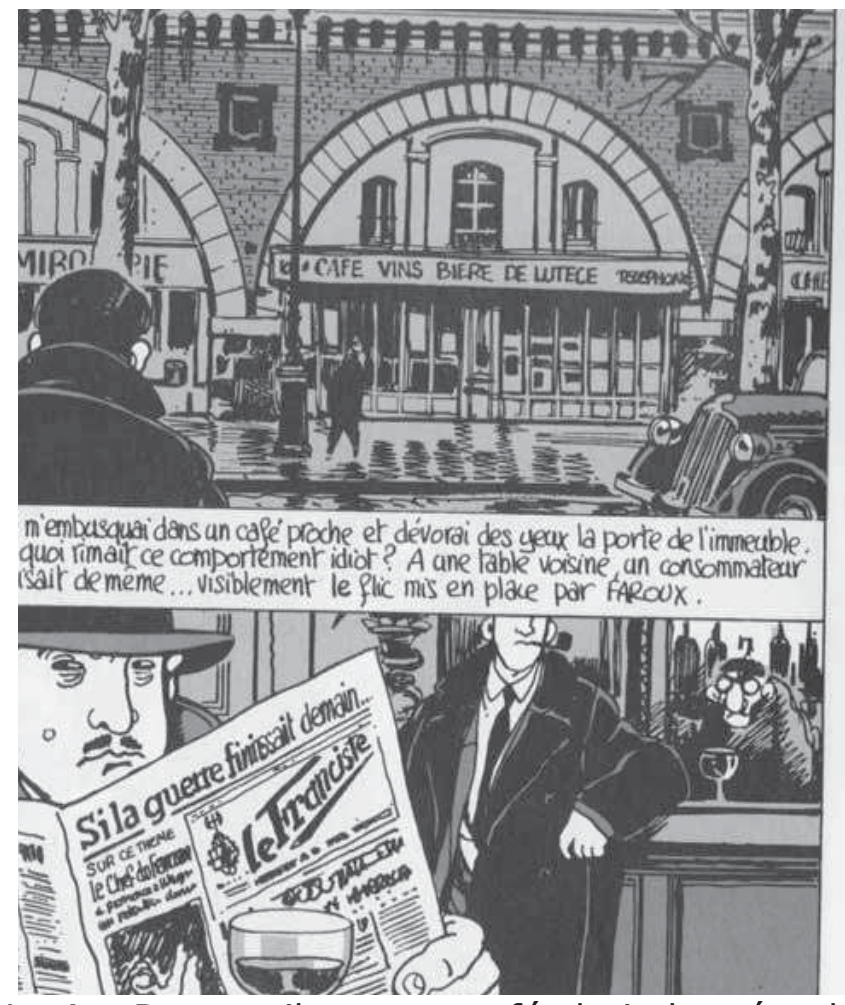

Figura 6. La Av. Dumesnil con sus cafés bajo las vías de aparente normalidad. Sin embargo en su interior se lee el periódico colaboracionista. 

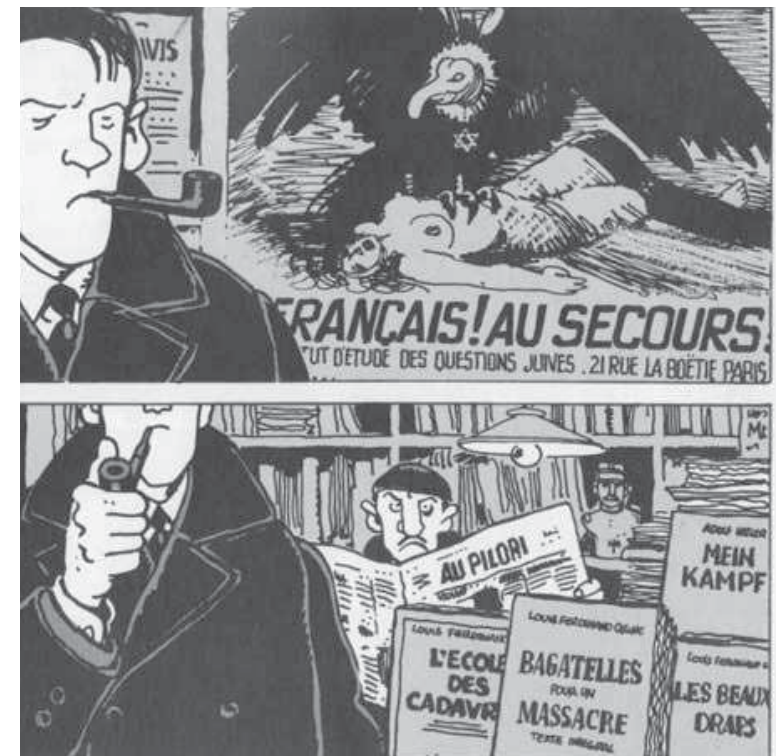

Se passai ma joarnée à farie toutes les libbines que je trouvai sur mon

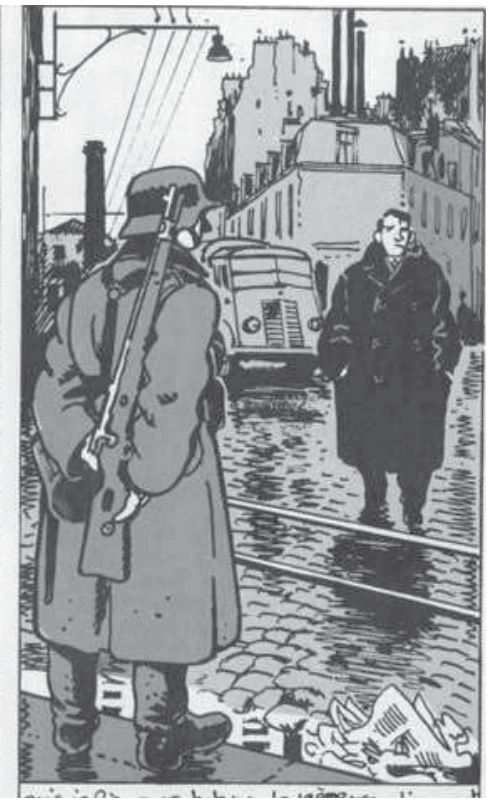

Figura 7. Tres imágenes del París ocupado. Carteles antisemitas (la República Francesa estrangulada por un buitre con la Estrella de David al cuello), un soldado alemán y una librería con obras de Celine y del propio Hitler donde el librero lee el semanario antisemita Au Pilori.

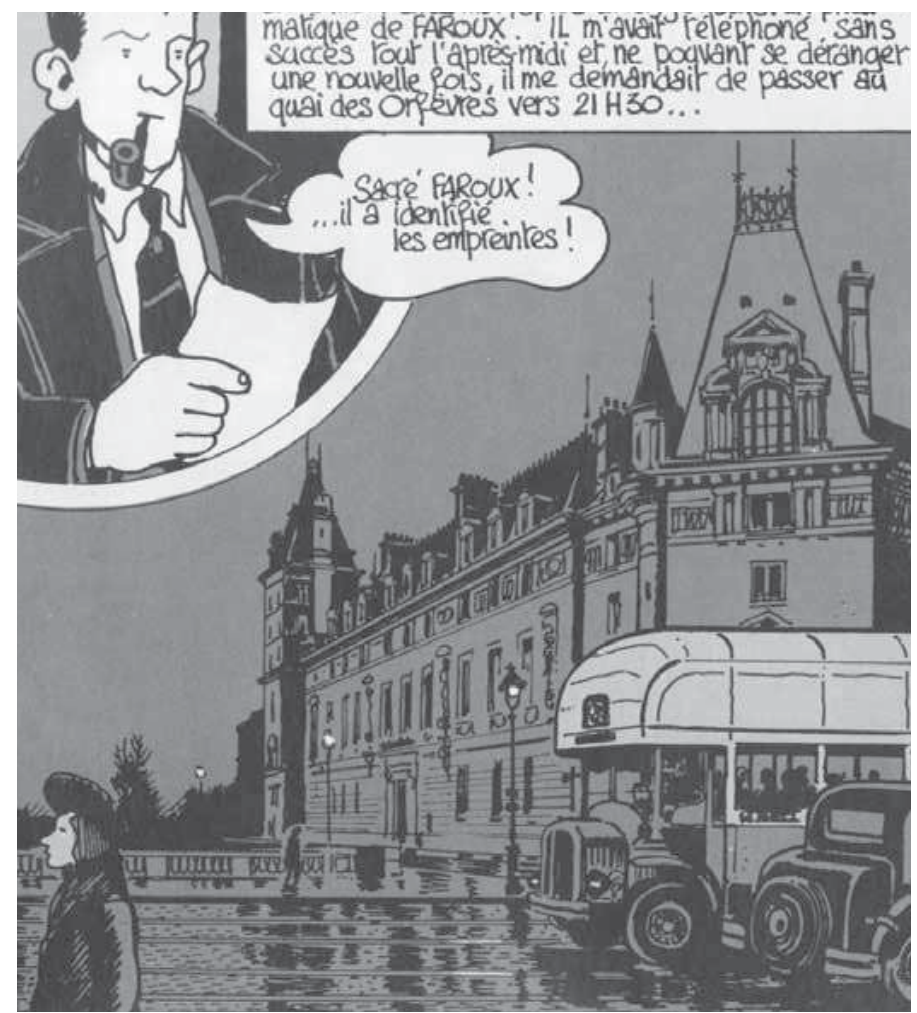

Figura 8. El célebre Quai des Orfèvres, sede de la policía de París. 


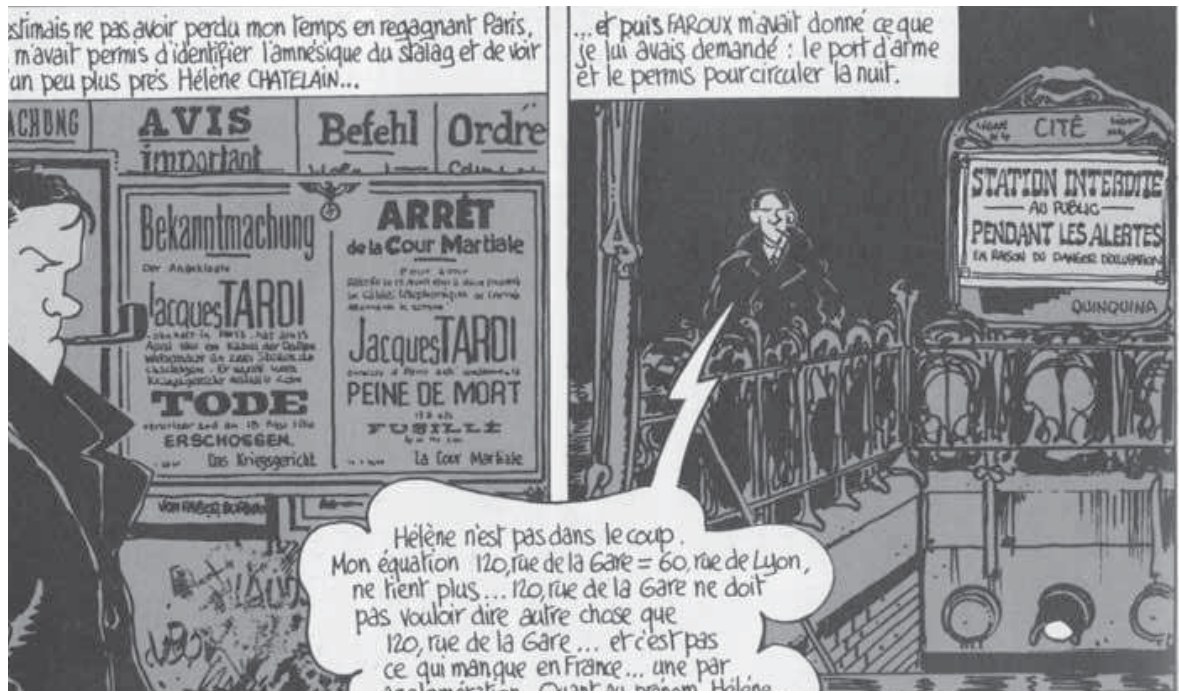

Figura 9. En la viñeta de la derecha vemos una estación de metro prohibida durante las alertas y a la izquierda, un bando de la Corte Marcial bilingüe con el águila y la esvástica (además de la broma del autor, que se incluye como condenado a muerte).

assez salisfair, ge flanar sur les grands boulevards avant de entrer chez mol.

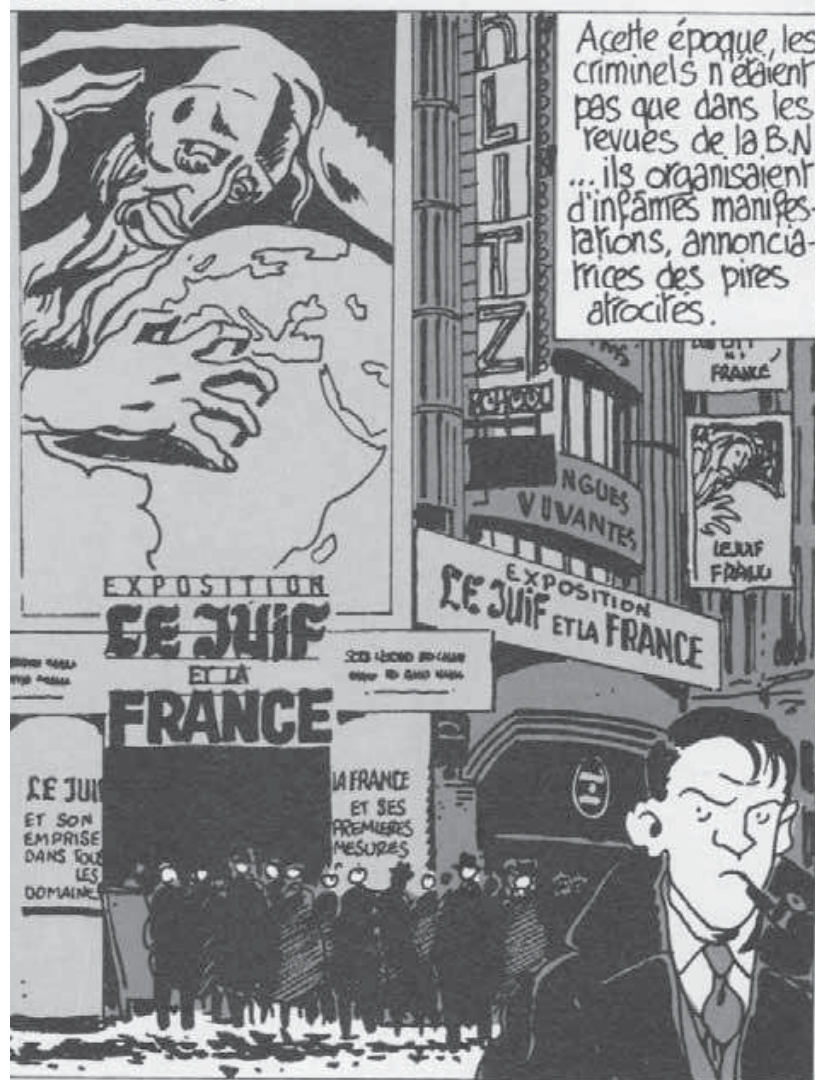

Figura 10. Mientras en el fondo se ve una larga cola entrando a la tristemente célebre exposición "El judío y Francia", especie de justificación histórica del antisemitismo francés, Nestor Burma la observa de reojo pero sigue con su investigación policial. 
La prensa, los espectáculos, el cine para soldados alemanes generan intertextos urbanos con los bocadillos que leemos en paralelo. De hecho, en un guiño irónico, semejante a los cameos cinematográficos, Tardi se incluye entre los perseguidos por los alemanes apareciendo su nombre en uno de los carteles (figura 9). Pero luego aparecen también el pasaje Choiseul (figura 3); la rue de Lyon con la plaza de la Bastille al fondo (figura 5); el Quai des Orfèvres donde se sitúan los cuarteles de la policía (figura 8); el león de Belfort en la plaza Denfert-Rocherau, símbolo de la resistencia francesa en la guerra contra Prusia (figura 11); la Conciergerie en la île de France (figura 12) y, por fin, la rue de Rivoli llena de banderas nazis (figura 13). Espacios de libertad o bien espacios simbólicos ocupados semánticamente por la propaganda y emblemática nazi.

No podemos detenernos en un análisis exhaustivo de la complementación visual de las alusiones veladas en el texto. Un ejemplo claro es el de la viñeta inferior izquierda de la figura 7 . En la novela de Malet el detective recorre las librerías sin aludir al fuerte contenido antisemita y fascista de las publicaciones que se podían encontrar en ellas (como leemos en la viñeta el texto tomado de la novela), pero la imagen nos permite ver y leer los títulos de las obras que se encontraban en los escaparates. También en la figura 10 la alusión general a "les criminels" se dota de resonancia cuando Burma tiene detrás la innoble exposición "El judío y Francia".

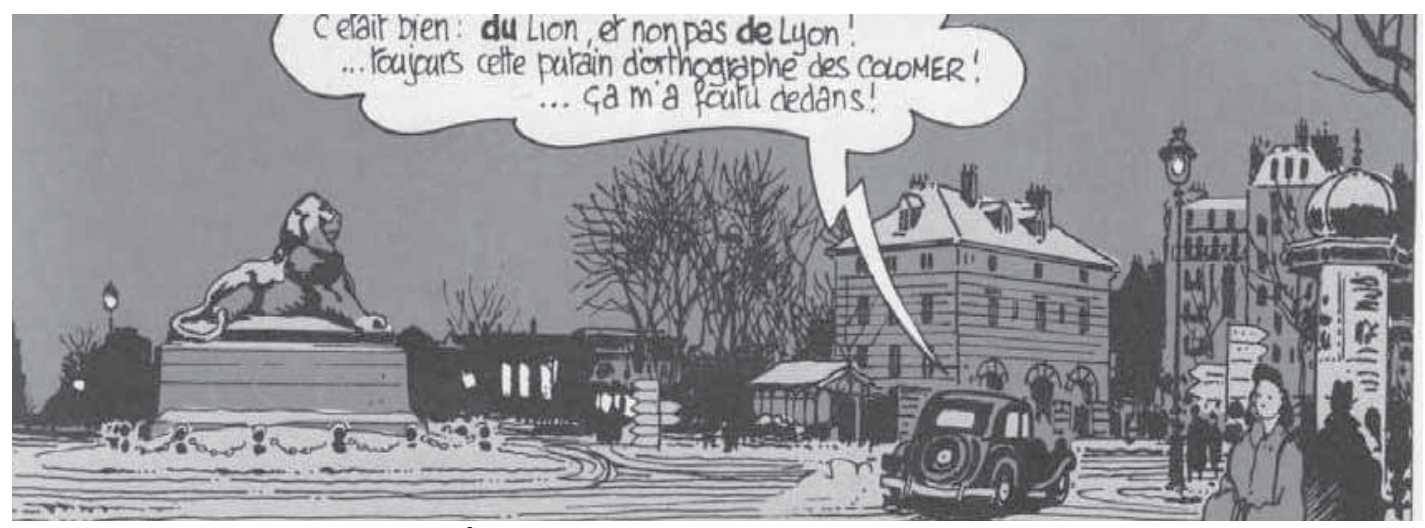

Figura 11. El león de Belfort en la plaza Denfert-Rocherau. 


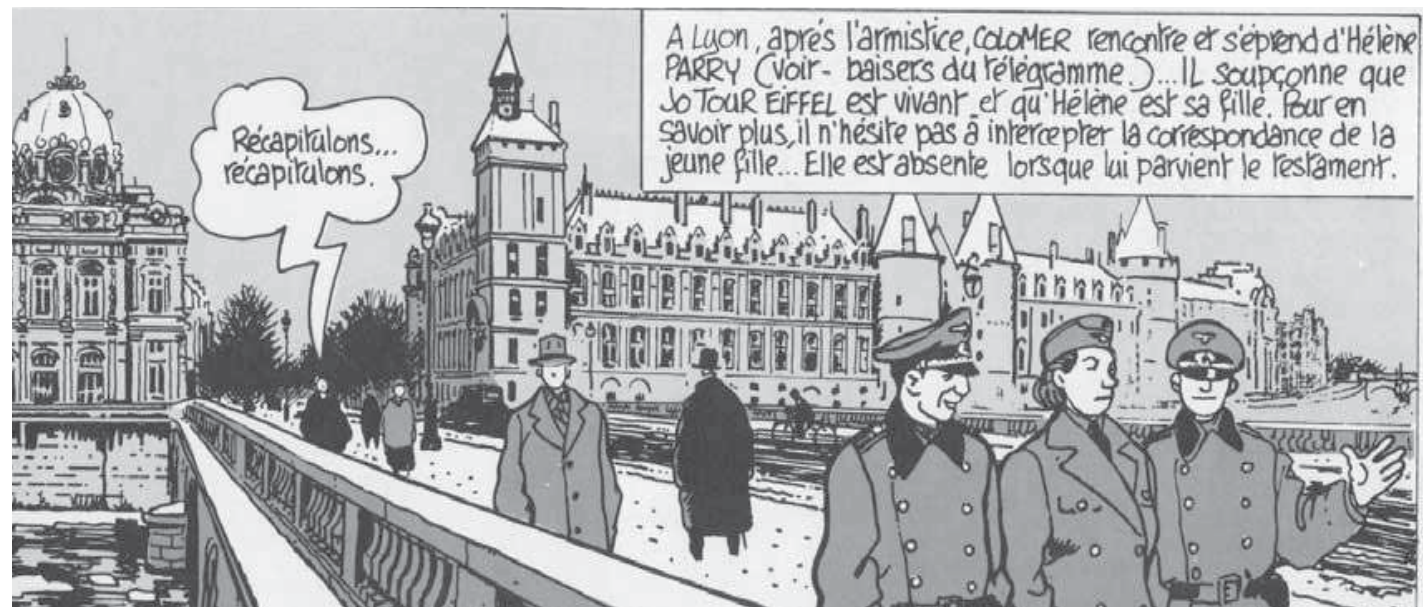

Figura 12. El Pont Neuf y al fondo la Conciergerie con oficiales alemanes paseando.

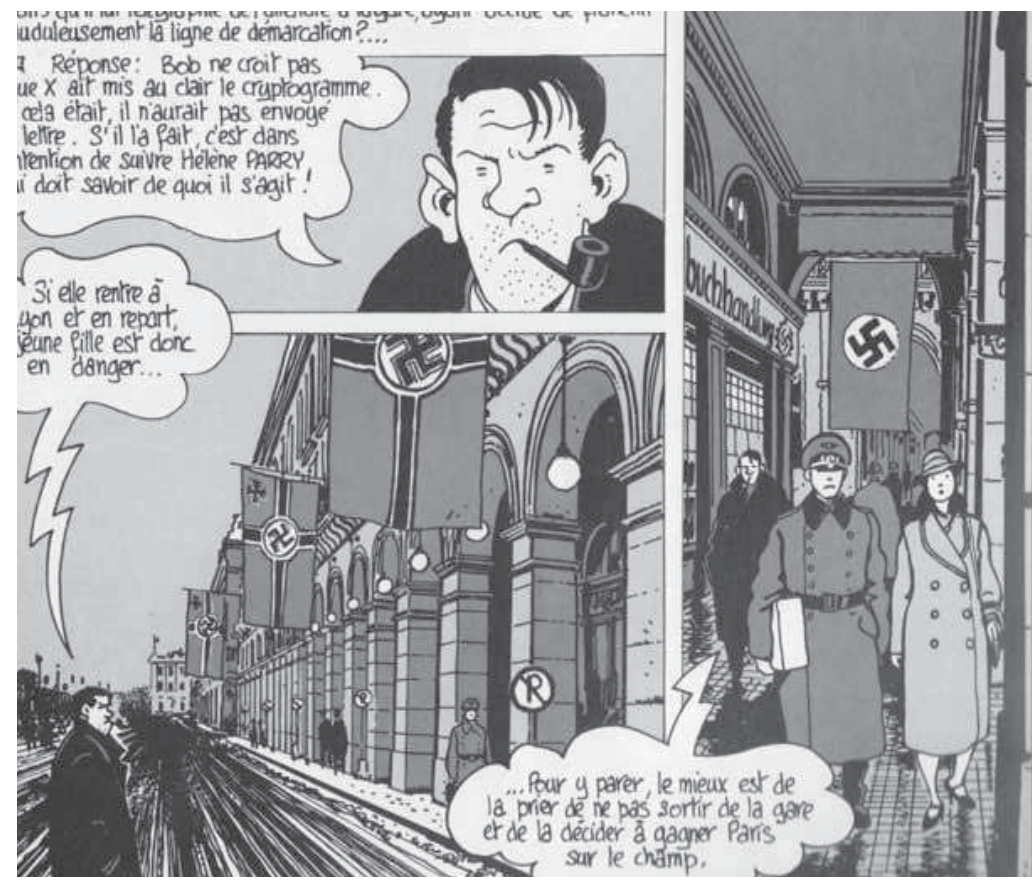

Figura 13. La rue de Rivoli con banderas nazis.

Este juego semántico entre primer y segundo plano se aprecia claramente en la última plancha. Cuando la intriga se ha resuelto el fondo desaparece, la asistente de Burma, Hélène, le pregunta qué significa "Fiat lux" (hágase la luz), irónico nombre de la agencia investigadora de Burma, pero que se puede interpretar como todo un anhelo de esperanza desde la Ciudad Luz en el oscuro momento histórico. Así, pasamos, sin solución de continuidad, del plano medio que muestra a los dos personajes sobre un fondo gris a la última viñeta del álbum (figura 14). En primer plano, vemos señales de tránsito alemanas, y en segundo plano, un establecimiento de productos alimenticios con una larga cola a sus puertas. Se ha 
solucionado el enigma pero aún queda mucho para la liberación. A continuación reproducimos la plancha completa de la última página.

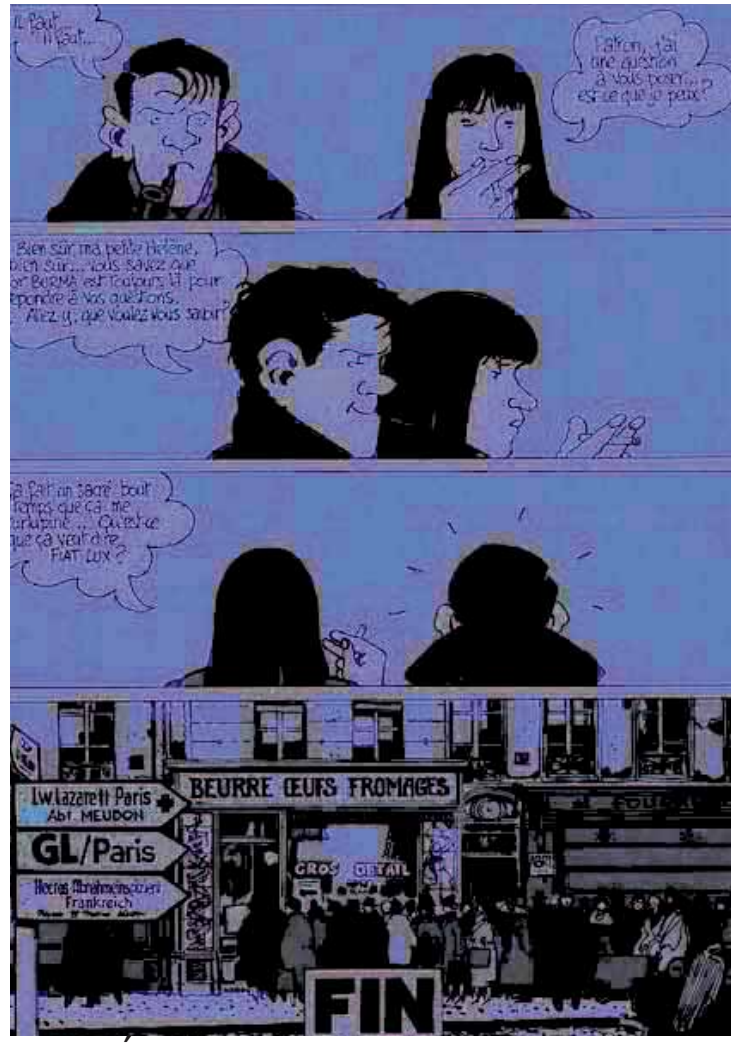

Figura 14. Última plancha de 120, rue de la Gare.

\subsection{París en Le petit bleu de la côte Ouest}

El ejecutivo de Manchette, a diferencia de tantos otros, no vive en los suburbios, pero tiene un trabajo asfixiante sin ilusión de cambio (Gorrara 2003: 64-72). En este sentido, la impresionante primera plancha del álbum ya nos sitúa en la dinámica visual de la obra, in medias res. Georges Gerfaut conduce por el bulevar periférico exterior (según la traducción española, una suerte de circunvalación o "M-30" parisina). El coche funciona claramente como su mundo interior y su espacio vital es un non-lieux, en términos de Marc Augé, circular, sin salida (figuras 15 a 17). Posteriormente vemos su hogar, un edificio a la americana, sin señas de identidad, del cual el personaje, perseguido por el azar, huye (figura 18). Buena parte del relato se desarrolla fuera de la capital. Abandona a su familia, se entrega a un alcoholismo ya latente y a una violencia que no respeta la idea de institucionalidad o justicia, se ha visto involucrado en una trama criminal que le es del todo ajena; de hecho, no es una víctima en el sentido clásico. No hay heroicidad ni ideales sino venganza y supervivencia en un mundo delictivo que se puede leer como metonimia del descarnado mundo de los ejecutivos de empresa, dispuestos a todo por ascender. 
Fuera de algún cartel y alguna vista de calle, París sólo aparece retratada en el Boulevard Periphérique donde las planchas, al comienzo y al final del relato circular (las tres primeras y las tres últimas), se pintan de negro para marcar un estado otro, sin duda donde el espacio está detenido en un eterno retorno y que incluso se podría entender como un espacio onírico.

Fuera de este espacio cargado semánticamente sólo vemos el deslavado edificio de apartamentos en el Bd. Auguste Blanqui, a pocos pasos de la Place d'Italie (el edificio existe), la irrupción de la prensa, la sociedad del espectáculo, superpuesta en una viñeta (figura 19), y la Avenue d'Italie con el desconcertante edificio-hito de la Tour Super-Italie (figura 20), para regresar al círculo sin salida.

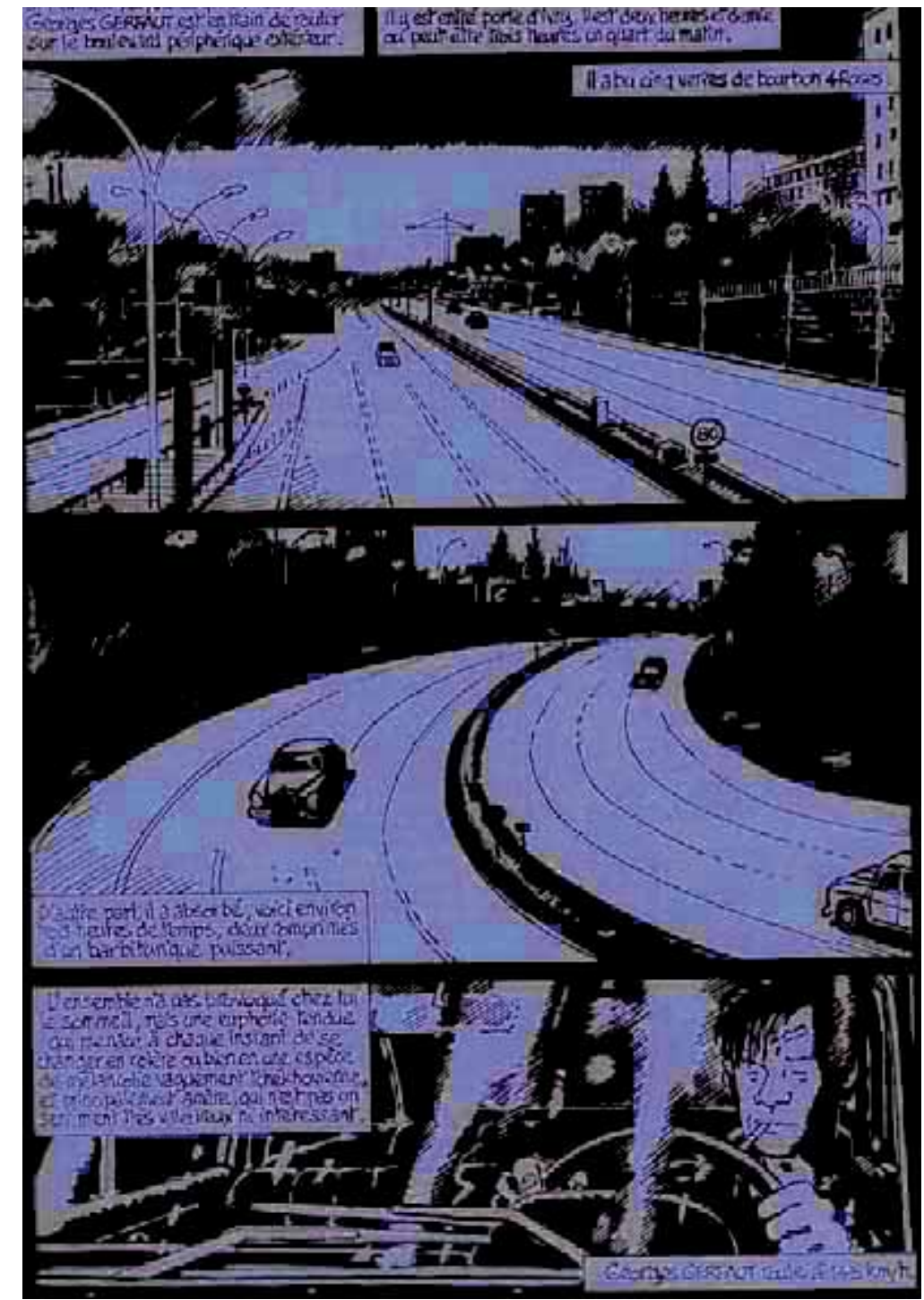

Figura 15. Bd. Périphérique. Primera plancha. 


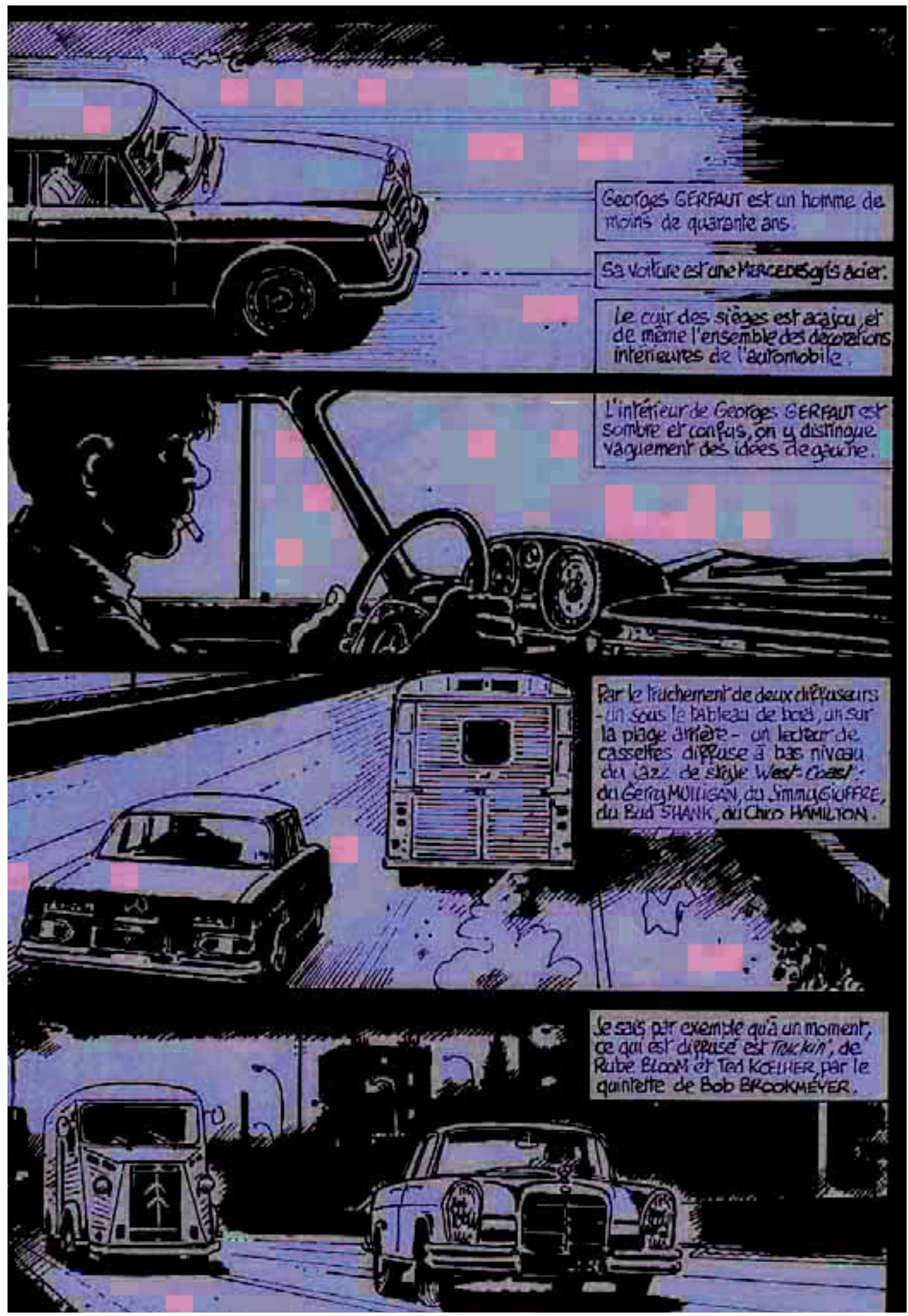

Figura 16. Segunda plancha. 


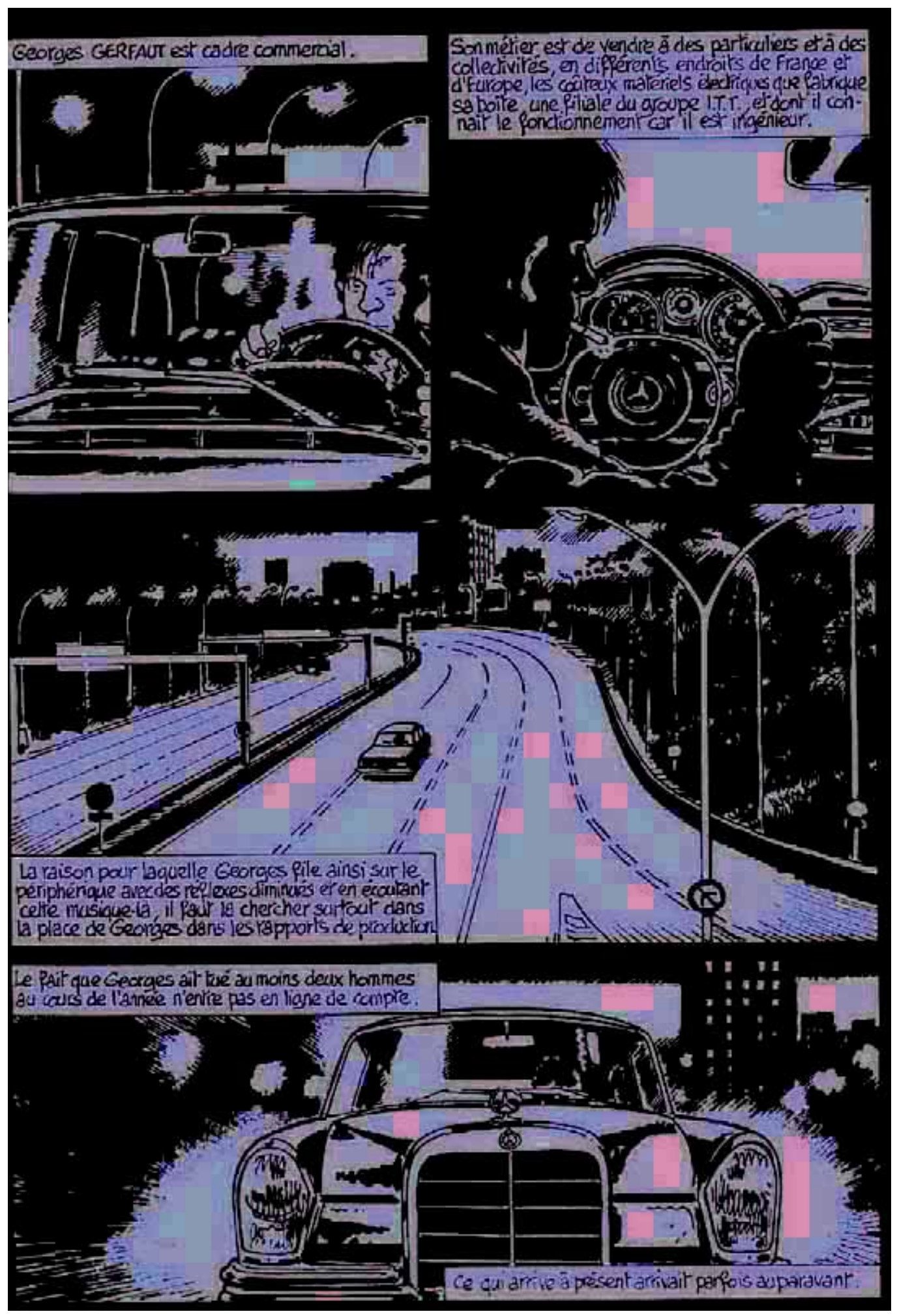

Figura 17. Tercera plancha. 


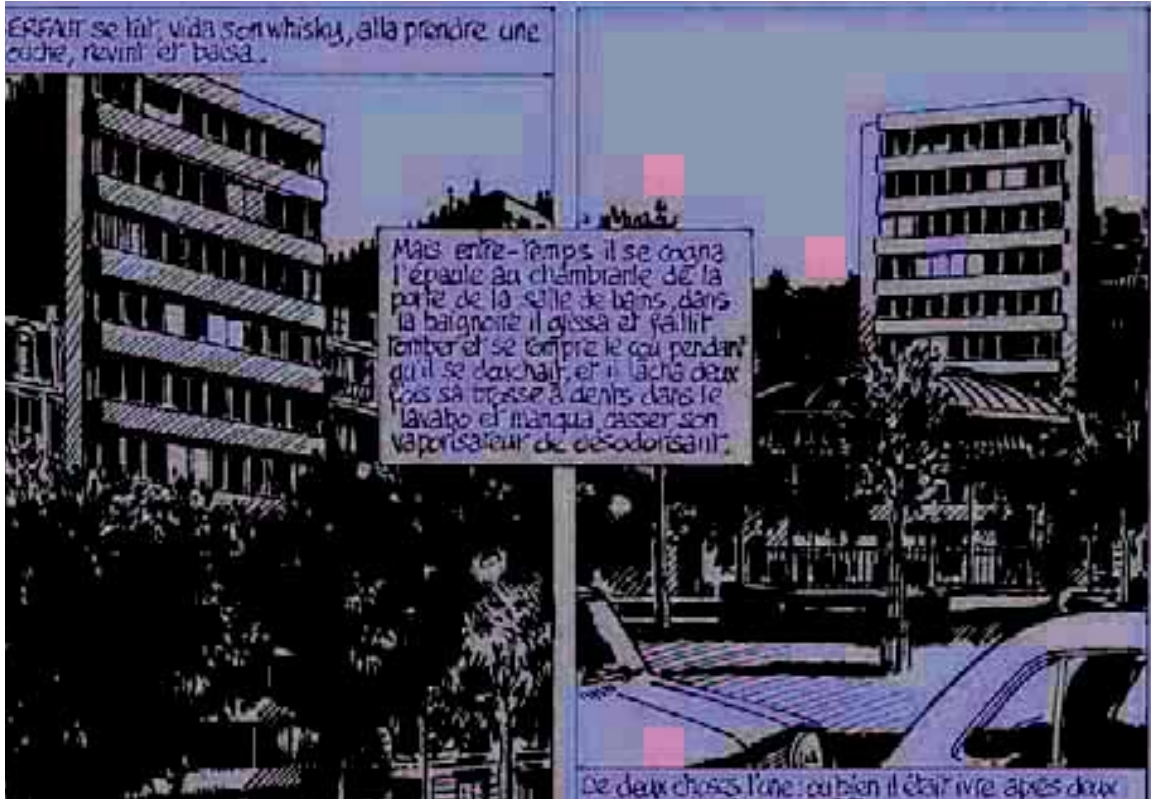

Figura 18. El edificio de Garfaut, sin mayores señas propias.

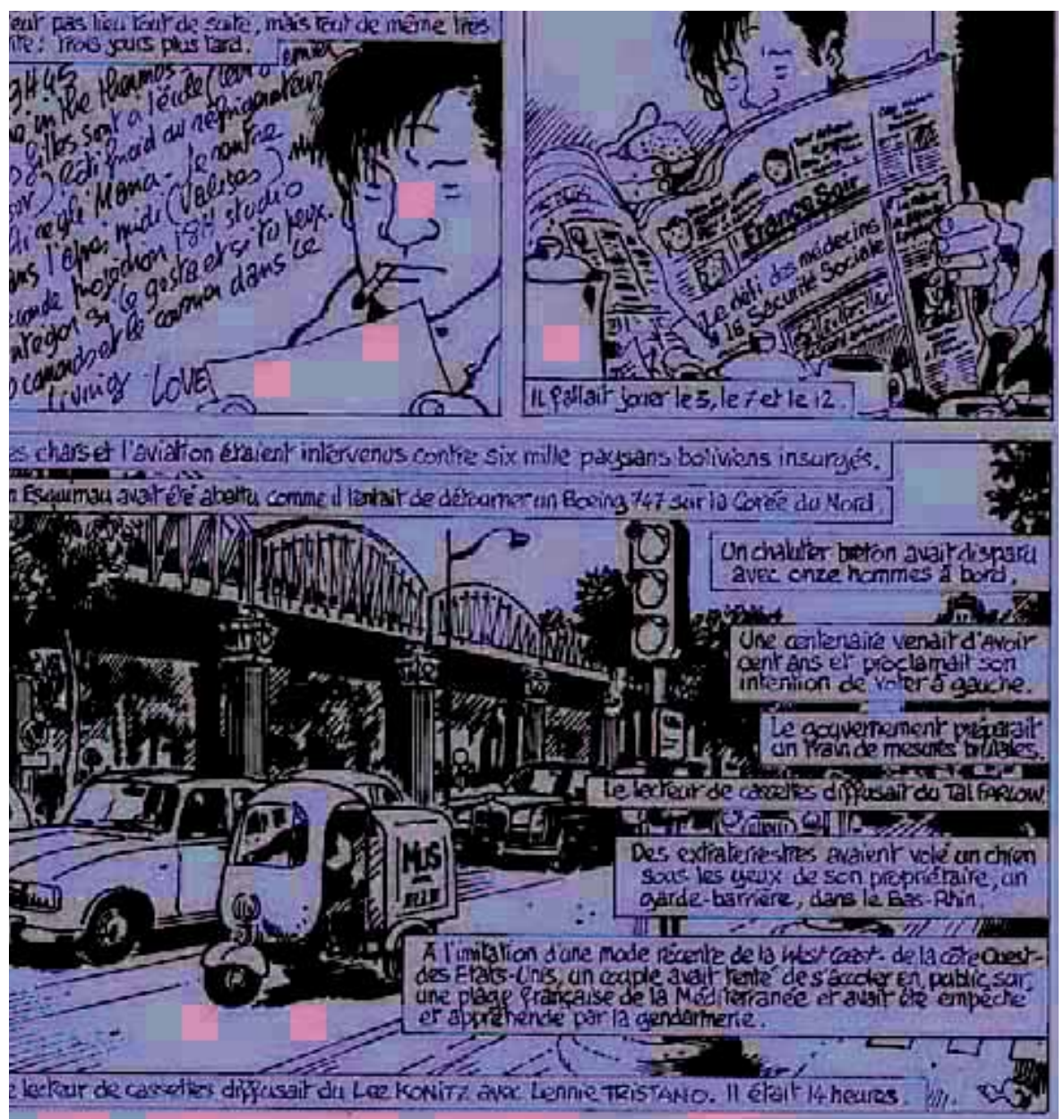

Figura 19. El Bd. Vincent Auriol. 


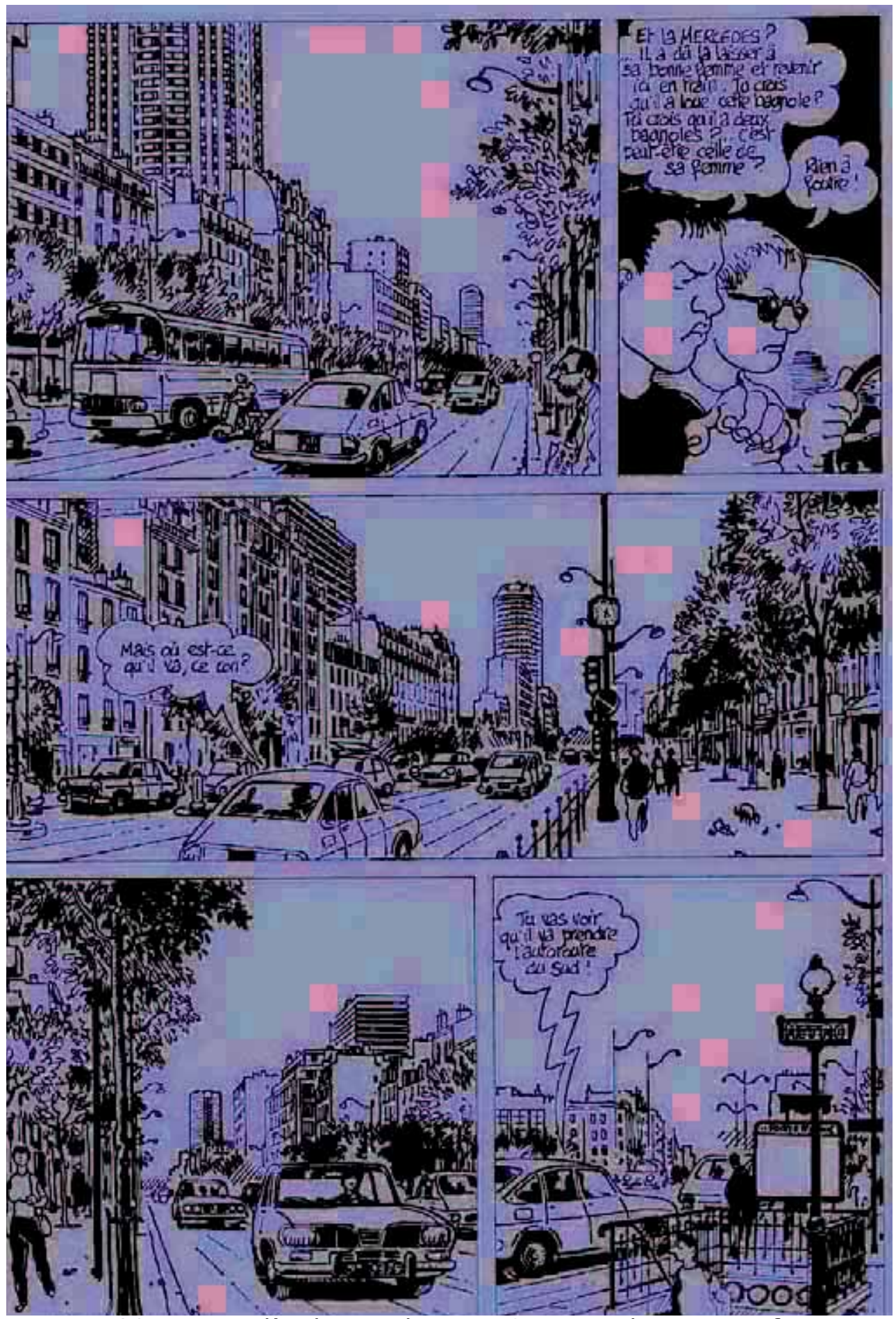

Figura 20. La Av. d'Italie con la torre Super-Italie como referente. 


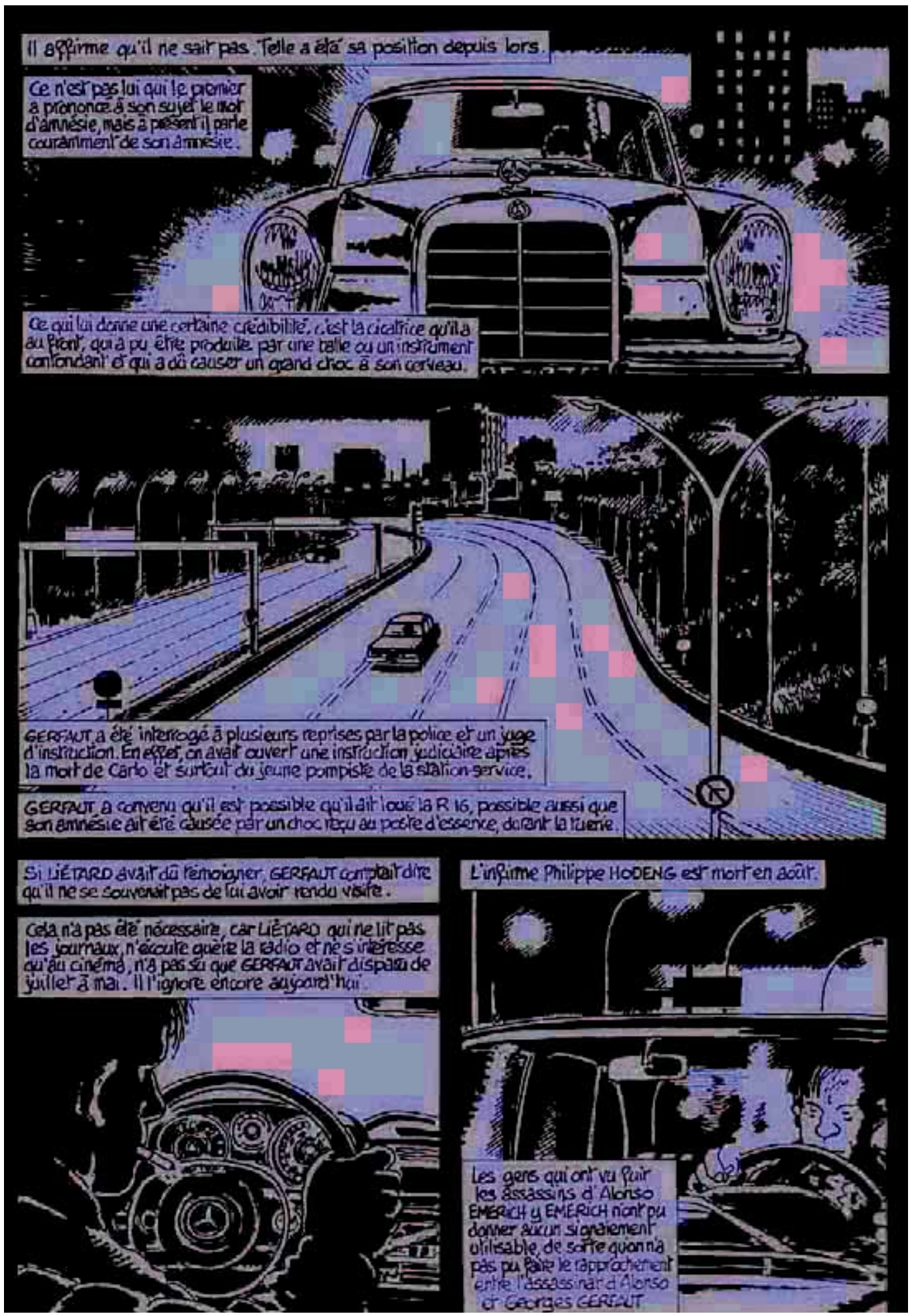

Figura 21. Bd. Périphérique. Antepenúltima plancha. 


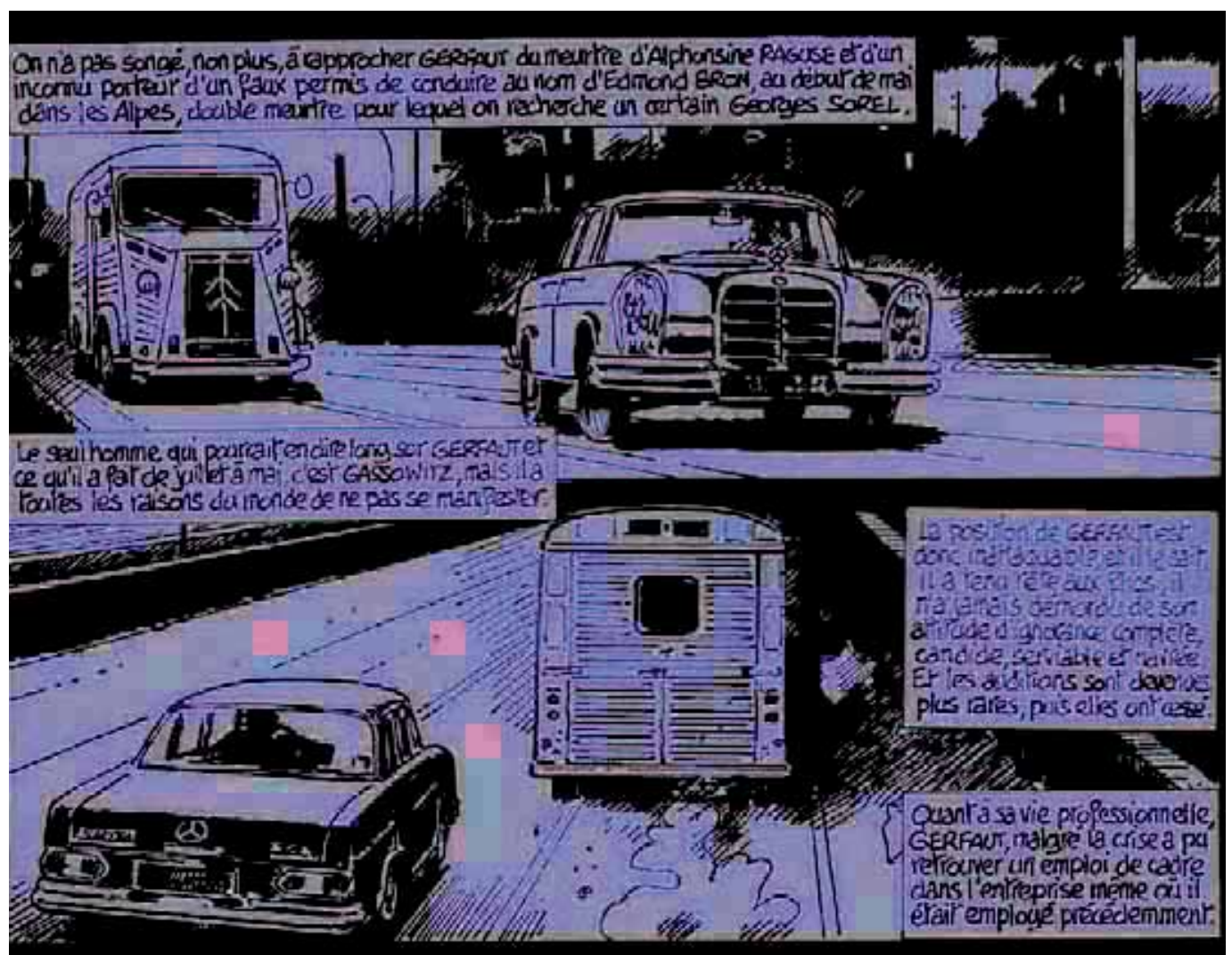

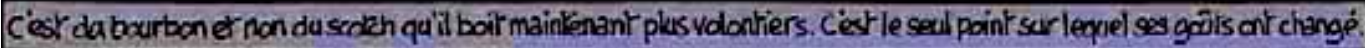

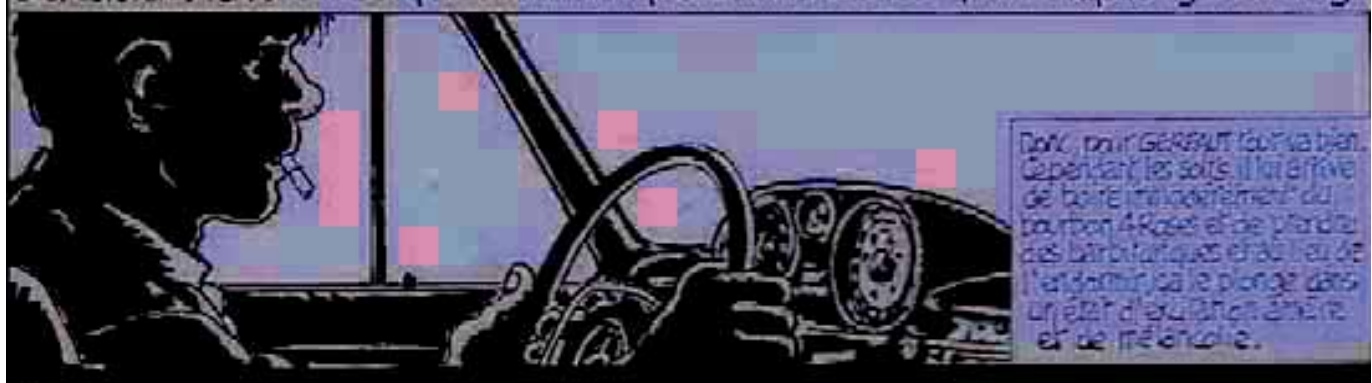

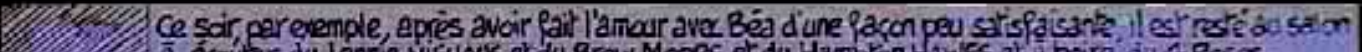

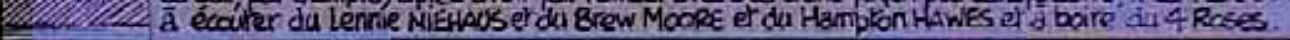

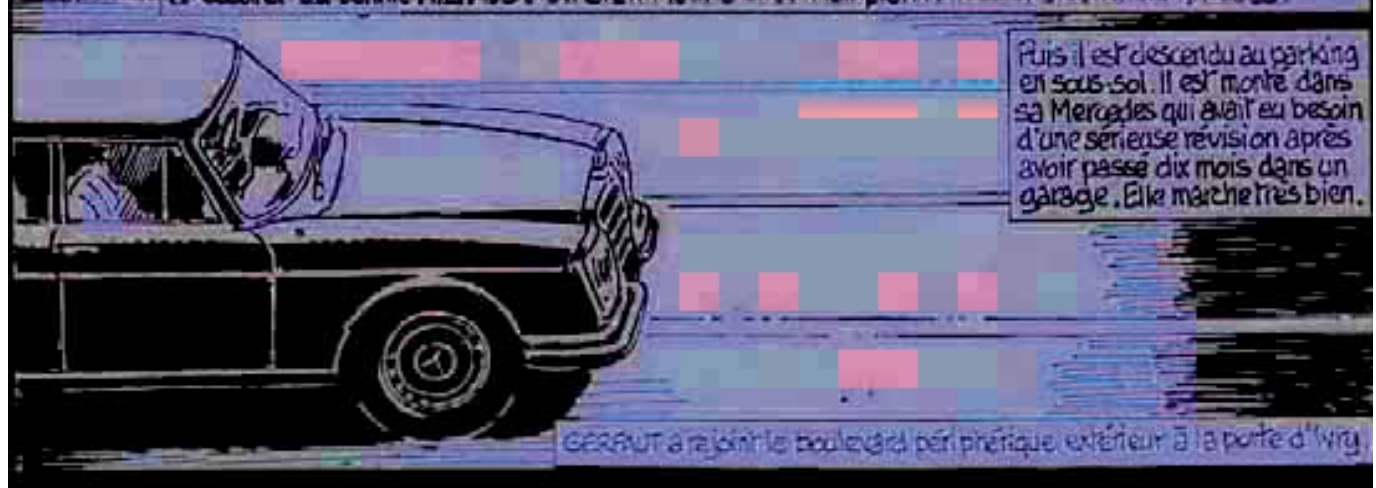

Figura 22. Penútima plancha. 

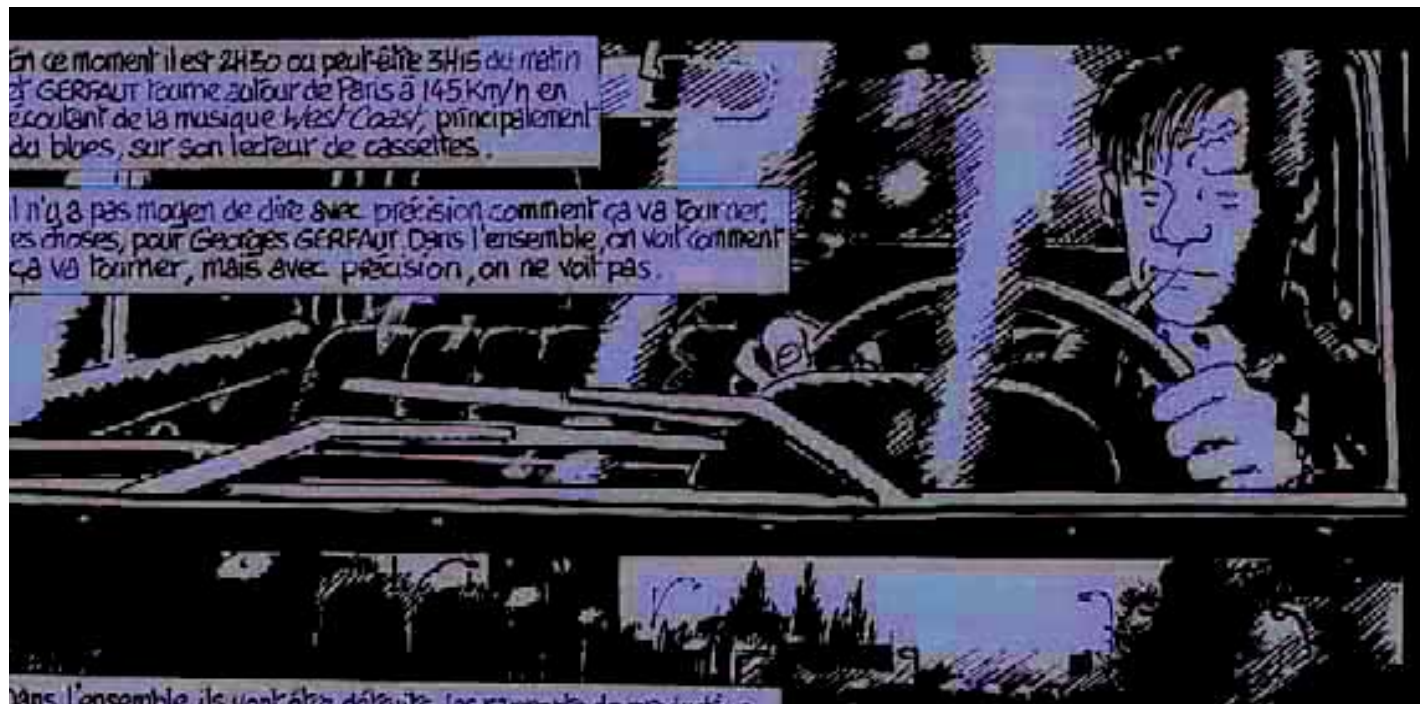

lans l'ensemble ils vont étie delruils, les rapoorts de prodaction

ans lesquels il faur chercher la raison prur laguelle ceorges file

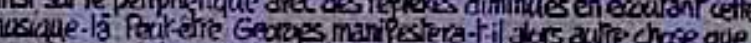
a patence or la servilite quil a lajjours maniparces.
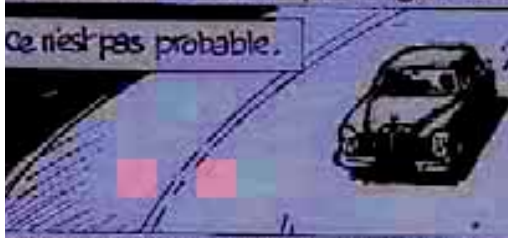

Jine fois, dans un contexte douterux, il a vecus une iventure mavivementze et saigrante; ed ensaite aut ce cuil a révé a paire, cest rentrar as betcail. If maintenant du bercail, il altend.
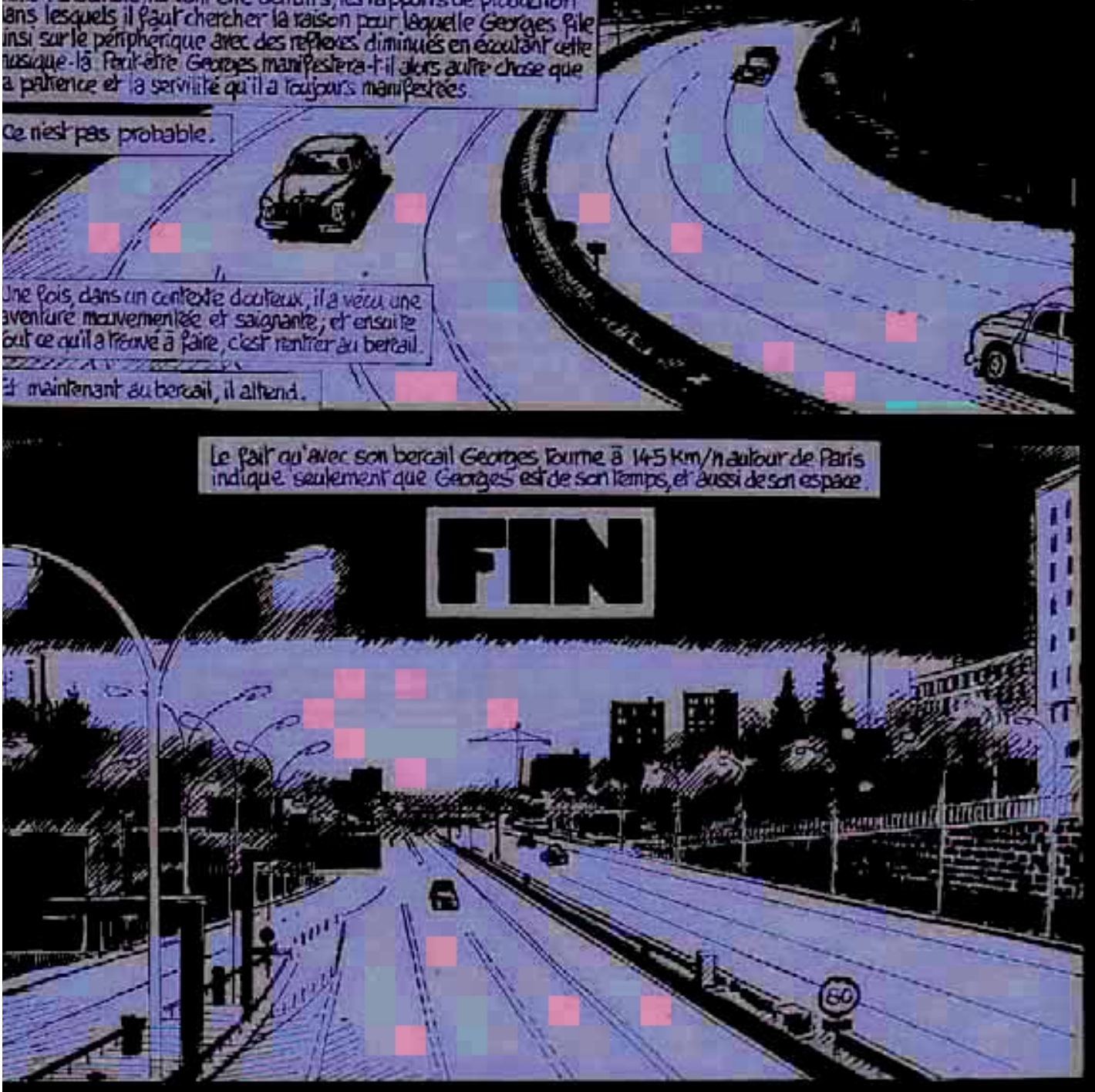

Figura 23. Última plancha. 


\section{Desplazamiento y centro: L'Opéra Garnier}

Podemos ver cómo, de 120 a Le petit bleu, se pasa de una imagen de ciudad gris que está invadida pero que desea ser reapropiada por sus verdaderos habitantes a una ciudad que sólo se puede habitar en sus márgenes y no tiene más imagen que un no-lugar. Hemos pasado de una imagen de ciudad que denuncia tanto la sobreposición, la "ocupación semántica", de la propaganda nazi en las calles, como reivindica los espacios de memoria de los franceses sometidos, hasta una ciudad saturada de información de consumo y que no permite que sus habitantes la habiten realmente, toda la ciudad es un nolugar y el único espacio para el ejecutivo alienado es el margen, en movimiento, sin rumbo. Respecto al uso de la escritura, en sus distintas posibilidades dentro de la viñeta más allá del bocadillo, Benoît Peeters, uno de los mayores teóricos del medio, ha dicho que es la característica fundamental del trabajo de Tardi (Peeters 2002: 147), destacando los múltiples niveles narrativos superpuestos que esta elaboración permite (2002: 150) y que son visibles en su constante articulación de los espacios representados. Tanto en el contrapunto entre imagen y palabra en la investigación policial en el París ocupado como en el flujo de conciencia que acompaña el traumático viaje circular.

Sin embargo, no todo es oscuro. Curiosamente el espacio de identificación, lo que Bachelard llamaría el espacio feliz, es el mismo en ambas visiones de la ciudad. Los espacios del placer, de la memoria, más afectiva que histórica (no parece que la Opéra Garnier tenga un valor socio-político tan fuerte como muchos otros monumentos parisienses), son el punto de convergencia donde ambos personajes, y quizás el propio autor Tardi, encuentran un espacio de identidad con la ciudad. En términos de Pierre Nora y Marc Augé, la Opéra se convierte en lugar de memoria, personal, afectiva. A pesar de la distopía generalizada que representan ambas obras, donde los personajes están constantemente fuera de lugar, en un espacio alienado o en sus márgenes, en la Opéra Garnier dan señales de reconocimiento del espacio como propio. A pesar de los cambios que la estética nazi impone sobre el París ocupado en 120, Tardi sitúa a Burma alejándose de una Opéra saturada por los carteles alemanes pero cantando "Paris sera toujours Paris", quizás la clave de resistencia que articula toda la obra. Del mismo modo, cuando Gerfaut se baja del metro frente a la Opéra, quien no aparece en cuadro, por cuanto lo que vemos es su mirada en una "visión subjetiva", el narrador del relato de Manchette dice: "Il éprouvait un grand plaisir à se retrouver en ville" (figura 24). En ninguna de las dos narraciones de Malet y Manchette, los hipotextos, se encuentra una referencia directa a la Opéra Garnier como el espacio de estas pequeñas epifanías cotidianas, sin embargo Tardi lo carga de significado en ambos casos a pesar de la diferencia de los puntos de vista. 


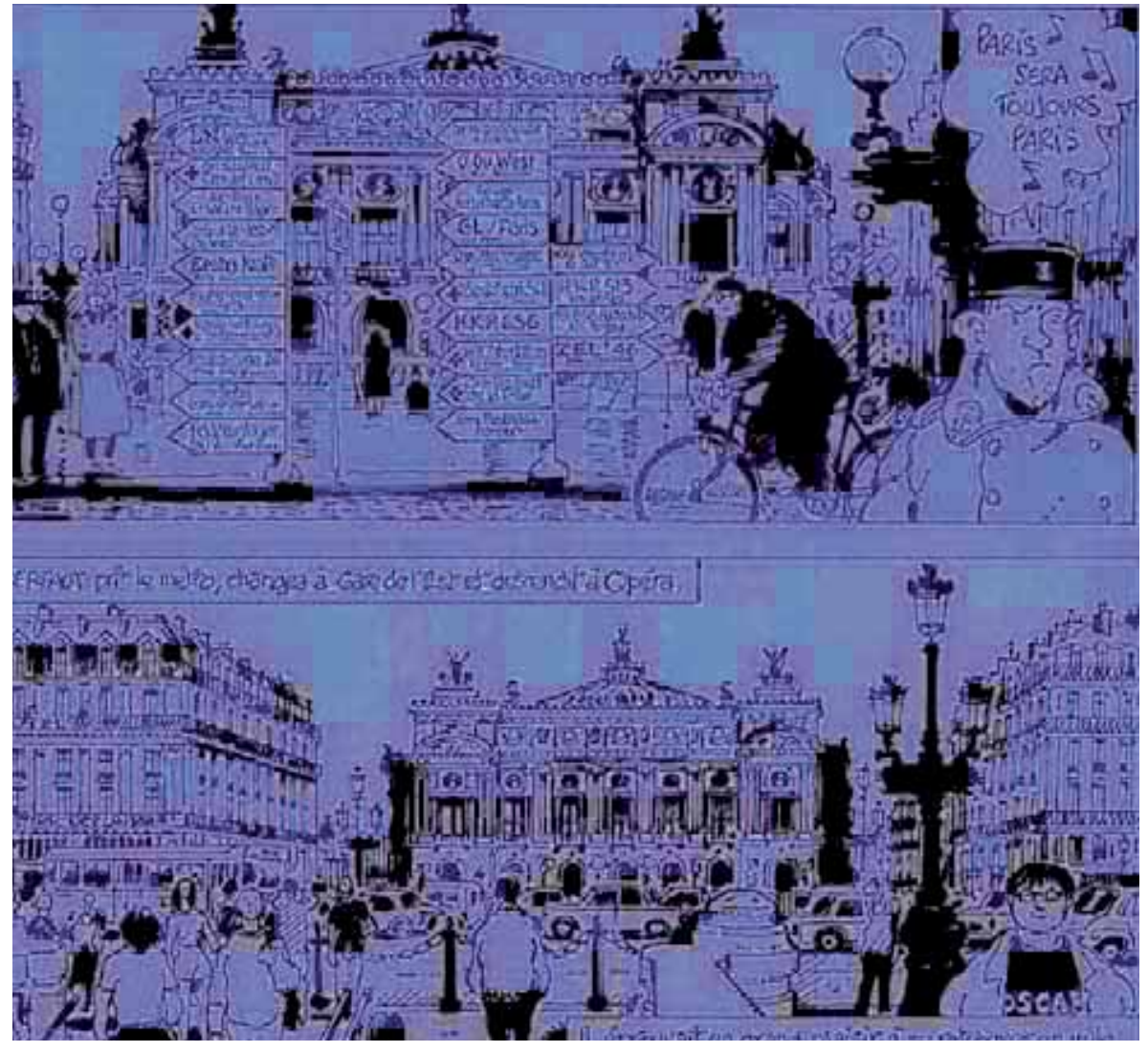

Figura 24. Opéra Garnier.

En el siguiente esquema hemos intentado sintetizar el desplazamiento de la representación visual de acuerdo a la narración y los cambios socio-históricos.

istórico-Social

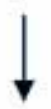

iudad Semántica

\section{csyuemia ue uesplacalineilu}

\section{Ocupación \\ Ideas de patria, libertad, opresión nazi.}

Centro de la ciudad, lieux de mémoire, imaginario integrador. Esperanza en el futuro y solución del crimen.

\section{"Malaise des cadres" Post-colonialismo, post mayo del 68 , desencanto social.}

\section{Carretera periférica,} circulo, espacio y tiempos cerrados. Non-lieu. Individualista atrapado. No se soluciona el crimen, sólo se cumple la venganza. No hay sentido. 
"Georges es de son temps, et aussi de son espace", son las últimas palabras de Le petit bleu. Si 120 nos recuerda la ocupación y muestra la posibilidad de solucionar el crimen como una metáfora de la salida de la situación de crisis política y social, en un movimiento lineal en el tiempo histórico, por el contrario Le petit bleu marca un tiempo circular, opresivo, del que ya no se puede salir. De este modo el tiempo, histórico y narrativo, se ve espacializado en la puesta en escena de Tardi en ambas obras. En un caso un catálogo de lugares de memoria que deben ser rehabilitados y que son conocidos por los lectores contemporáneos en su estado "libre". Por lo tanto, sabemos que la oscura situación presentada tendrá fin. En el otro caso, el espacio-tiempo circular de la avenida periférica donde encontramos atrapado al protagonista al principio y final de una obra constituida en sí misma como circular es inquietante, ya que la novela, escrita en 1976, se adapta en 2005 y si no es por los mínimos marcadores históricos, como la moda o el modelo del coche, podríamos pensar que el indignado Gerfault sigue ahí, que el turbio paso de Gerfault de ser otro ejecutivo descontento a convertirse en un descontrolado asesino podría suceder hoy, mejor dicho, esta noche.

\section{Bibliografía}

BOILEAU, Pierre; y NARCEJAC, Thomas (1964): Le roman policier. Paris: Payot.

DOUVRY, Jean-François (1988): Rendez-vous: 120, rue de la Gare. Autopsie d'une adaptation. Tournai: Casterman.

EISNER, Will (2007): El cómic y el arte secuencial. Barcelona: Norma.

GORRARA, Claire (2003): The roman noir in post-war French culture. Oxford: Oxford University Press.

PEETERS, Benoît (2002): Lire la bande dessinée. Manchecourt: Flammarion.

RAMÍREZ, Juan Antonio (1991): Edificios y sueños. Estudios sobre arquitectura y utopía. Madrid: Nerea.

REY, Alain (1978): Les spectres de la bande, essai sur la B. D. Paris: Minuit.

TARDI, Jacques (1988): 120, rue de la Gare. Tournai: Casterman. (2005): Le petit bleu de la côte Ouest. Tournai: Casterman. 